OPEN ACCESS

Edited by:

Longhuo Wu,

Gannan Medical University, China

Reviewed by:

Md Jamal Uddin,

Ewha Womans University, South

Korea

Kok Yong Chin,

National University of Malaysia,

Malaysia

${ }^{*}$ Correspondence:

Xinan Zhang

zhangxa2725@163.com

Mingli Sun

sun18940103126@163.com

Specialty section:

This article was submitted to

Ethnopharmacology,

a section of the journal

Frontiers in Pharmacology

Received: 14 October 2021 Accepted: 01 December 2021

Published: 20 December 2021

Citation:

Tian Z, Zhang X and Sun M (2021) Phytochemicals Mediate Autophagy Against Osteoarthritis by Maintaining

Cartilage Homeostasis.

Front. Pharmacol. 12:795058.

doi: 10.3389/fphar.2021.795058

\section{Phytochemicals Mediate Autophagy Against Osteoarthritis by Maintaining Cartilage Homeostasis}

\author{
Zheng Tian, Xinan Zhang * and Mingli Sun * \\ School of Kinesiology, Shenyang Sport University, Shenyang, China
}

Osteoarthritis $(\mathrm{OA})$ is a common degenerative joint disease and is a leading cause of disability and reduced quality of life worldwide. There are currently no clinical treatments that can stop or slow down OA. Drugs have pain-relieving effects, but they do not slow down the course of OA and their long-term use can lead to serious side effects. Therefore, safe and clinically appropriate long-term treatments for OA are urgently needed. Autophagy is an intracellular protective mechanism, and targeting autophagy-related pathways has been found to prevent and treat various diseases. Attenuation of the autophagic pathway has now been found to disrupt cartilage homeostasis and plays an important role in the development of OA. Therefore, modulation of autophagic signaling pathways mediating cartilage homeostasis has been considered as a potential therapeutic option for OA. Phytochemicals are active ingredients from plants that have recently been found to reduce inflammatory factor levels in cartilage as well as attenuate chondrocyte apoptosis by modulating autophagy-related signaling pathways, which are not only widely available but also have the potential to alleviate the symptoms of OA. We reviewed preclinical studies and clinical studies of phytochemicals mediating autophagy to regulate cartilage homeostasis for the treatment of OA. The results suggest that phytochemicals derived from plant extracts can target relevant autophagic pathways as complementary and alternative agents for the treatment of $O A$ if subjected to rigorous clinical trials and pharmacological tests.

Keywords: autophagy, phytochemicals, Osteoarthritis, chondrocytes, inflammation

\section{INTRODUCTION}

Osteoarthritis $(\mathrm{OA})$ is a common degenerative joint disease occurring in the elderly population and is the most common cause of pain and disability worldwide. Its pathology is characterized by progressive cartilage degeneration, increased subchondral bone remodeling and bone redundancy formation (Kraus et al., 2015), which poses a great burden to the patient's family and society (Nelson, 2018; Jones et al., 2019). The main pathological features of OA include articular cartilage erosion, synovitis and subchondral bone degeneration (Hunter and Bierma-Zeinstra, 2019), but the exact mechanisms are not known. Available studies suggest that multiple pathological factors such as overloading, trauma, imbalance of inflammatory systems, and impairment of antiinflammatory pathways are involved in the development and progression of OA, leading to cellular senescence, reduced cell density, abnormal secretory activity, extracellular matrix (ECM) degradation, and impaired articular cartilage development (Goldring and Otero, 2011; Sofat et al., 2011; Doria et al., 2013; Robinson et al., 2016; Li et al., 2017b; Khan et al., 2018; Wang and He, 2018). 
Conservative treatment is currently the main treatment for $\mathrm{OA}$ and is mainly limited to pain control. Various drugs, such as Nonsteroidal anti-inflammatory drugs (NSAIDs), cyclooxygenase-2 (COX-2) inhibitors, glucosamine, steroids, and hyaluronic acid (Philp et al., 2017) have been used clinically to slow the progression of OA, but they are limited to pain control and do not reverse the effects of OA, and all have significant side effects with long-term use (Bert and Bert, 2014; Cutolo et al., 2015; Hunter and Bierma-Zeinstra, 2019). Joint replacement is the mainstay of treatment for advanced knee OA, and although it is effective, it is expensive and has a limited lifespan (Zhang et al., 2016; Nelson, 2018; Kloppenburg and Berenbaum, 2020). Therefore, there is an urgent need to explore new means of OA treatment.

Autophagy is a self-protective mechanism (Benderdour et al., 2015; Sohn et al., 2017) that relies on autophagosomes and lysosomes to efficiently maintain internal environment homeostasis by removing protein aggregates or unwanted cellular components (Zhi et al., 2018). Under hypoxia, nutritional deficiency, endoplasmic reticulum stress (ERS), or other pathological conditions, autophagy is activated to degrade dysfunctional intracellular components, thereby improving cell survival and function ( $\mathrm{Li}$ et al., 2019b). Currently, targeting autophagy-related pathways has been shown to be a new approach to treating diseases such as liver diseases and tumors, and has received widespread attention from researchers (Togano et al., 2021; Zhou et al., 2021a). During the development of OA, decreased chondrocyte autophagy leads to impaired cellular function, resulting in joint aging and dysfunction (Netea-Maier et al., 2016), indicating that autophagy plays an important role in the development of OA and is expected to be an important target for OA treatment.

Recently, relevant studies have found that phytochemicals play an important role in disease prevention and treatment by mediating the autophagic pathway (Zhang et al., 2015; Ranjan et al., 2019; Mao et al., 2020). In recent decades, due to the effectiveness of phytochemicals in disease prevention and treatment, botanical drugs and natural products are widely used as complementary and alternative medicines for the treatment of OA to function (Cameron and Chrubasik, 2014) and have received increasing attention in the last decade. Naturally sourced phytochemicals are both widely available and inexpensive, and provide a valuable source of lead compounds or adjuvant components for the development of new drugs against OA. In recent years, many studies (Chin and Pang, 2017; Jiang et al., 2020; Luk et al., 2020) have shown that phytochemicals derived from plants or botanical drugs may play an important role in the prevention or treatment of OA by activating autophagy through different mechanisms. However, there is no comprehensive review article reporting preclinical and clinical studies of phytochemicals improving OA by mediating autophagy-related pathways. Given the important role of autophagy in the progression of OA, we carefully reviewed phytochemicals from different plant sources that may help regulate autophagy-related signaling pathways and can be used to treat OA through improved cartilage. We searched the scientific literature for the last decade systematically using the authoritative internet databases of PubMed, Web of Science, and Embase by combining the keywords "autophagy", "osteoarthritis", and "plant". The primary search criterion was the application of phytochemicals of different plant origin for the treatment of OA through autophagy. These phytochemicals can be classified as polyphenols, flavonoids, terpenoids, coumarins, saponins, and small molecule compounds. Table 1 gives an overview of the resource profile and mechanisms of phytochemicals that mediate the autophagic pathway against OA, with species and family names according to the relevant literature based on www. theplantlist.org, http://www.plantsoftheworldonline.org/, http:// mpns.kew.org/mpns-portal/ (Rivera et al., 2014).

\section{AUTOPHAGY-MEDIATED CARTILAGE HOMEOSTASIS AND OA}

Chondrocytes are the most dominant cells in cartilage tissue and play an important role in maintaining matrix integrity, and abnormal chondrocyte function is closely related to the development of OA. Chondrocytes play an important role in maintaining cartilage metabolic homeostasis by maintaining the stability of cartilage tissue and ECM (Kim and Blanco, 2007; Caramés et al., 2010; Charlier et al., 2019; Rim et al., 2020). When certain pathological factors act on the cartilage matrix and alter its structure, chondrocytes respond accordingly. However, the ability of articular chondrocytes to maintain normal cartilage matrix structure and integrity is limited and decreases with age (Martel-Pelletier et al., 2016). Molecular changes associated with aging of articular cartilage, as well as mechanical and inflammatory factors, can lead to elevated levels of reactive oxygen species (ROS), induce mitochondrial damage and ERS, severely impair chondrocytes and their ability to regulate ECM release, and may ultimately trigger the cascade of chondrocytes apoptosis (Wu et al., 2014; Bolduc et al., 2019). Dysfunction occurring in chondrocytes, including decreased survival (Loeser et al., 2016), inadequate ECM production (Mobasheri et al., 2017) and excessive activation of proteases (Kim et al., 2014) also accelerate cartilage degradation and disrupt joint microarchitectural integrity, leading to the development of OA.

Autophagy is an evolutionarily highly conserved degradation system that relies on the degradation of dysfunctional organelles and biomolecules by lysosomes under the regulation of autophagy-associated genes (ATG) to remove protein aggregates and dysfunctional organelles to maintain cellular homeostasis and protect cells from apoptosis (Levine and Kroemer, 2008; Mizushima et al., 2008; Nakamura and Yoshimori, 2017). When cells are exposed to abnormal physiological conditions, such as external stress, nutrient deficiency, hypoxia and ERS, autophagy is activated and plays a key role in regulating energy and nutrition and maintaining energy metabolism in the body (Duan et al., 2020). It was found that autophagy has a protective effect on cells in an inflammatory environment by regulating the body's energy and nutrients and maintaining the body's energy metabolism (Nakamura and Yoshimori, 2017; Yu et al., 2018). The most common marker 
TABLE 1 | Phytochemicals improve cartilage homeostasis via mediated autophagy against OA in vitro/in vivo.

\begin{tabular}{|c|c|c|c|c|c|c|c|}
\hline & Phytochemical & Plant species, family & Model & Dosage range & $\begin{array}{c}\text { Active } \\
\text { concentration }\end{array}$ & Signal pathways/Mechanisms & References \\
\hline \multirow[t]{17}{*}{ Polyphenols } & Curcumin & $\begin{array}{l}\text { Curcuma longa L., } \\
\text { Zingiberaceae Martinov }\end{array}$ & $\begin{array}{l}\text { In vitro, IL-1 } \beta \text { induced rats } \\
\text { chondrocytes }\end{array}$ & $\begin{array}{l}5 \mu \mathrm{M}, 10 \mu \mathrm{M}, 15 \mu \mathrm{M}, \\
\text { and } 20 \mu \mathrm{M}\end{array}$ & $10 \mu \mathrm{M}$ & MAPK/ERK1/2 signal pathway & $\begin{array}{l}\text { Li et al. } \\
\text { (2017a) }\end{array}$ \\
\hline & & & $\begin{array}{l}\text { In vitro, IL-1 } \beta \text { induced rats } \\
\text { chondrocytes }\end{array}$ & $1.25-20 \mu \mathrm{M}$ & $10 \mu \mathrm{M}$ & - & $\begin{array}{l}\text { Chen et al. } \\
(2021)\end{array}$ \\
\hline & & & In vivo, DMM surgery mice & $\begin{array}{l}50 \mathrm{mg} / \mathrm{kg} \text { via oral } \\
\text { administration, once daily for } \\
8 \text { weeks }\end{array}$ & $50 \mathrm{mg} / \mathrm{kg}$ & AKT/mTOR pathway & $\begin{array}{l}\text { Zhang et al. } \\
\text { (2018a) }\end{array}$ \\
\hline & & & $\begin{array}{l}\text { In vitro, IL-1 } 1 \beta \text { induced rats } \\
\text { chondrocytes }\end{array}$ & $10 \mu \mathrm{M}$ & $10 \mu \mathrm{M}$ & & \\
\hline & & & In vivo, HFD rats & $\begin{array}{l}200 \mu \mathrm{g} / \mathrm{kg} \text { body weight and } \\
400 \mu \mathrm{kg} \text { body weight via } \\
\text { joint injection }\end{array}$ & $\begin{array}{l}200 \mu \mathrm{g} / \mathrm{kg} \text { body } \\
\text { weight }\end{array}$ & $\begin{array}{l}\text { E2F1/PITX1 pathway and AKT/ } \\
\text { mTOR pathway }\end{array}$ & $\begin{array}{l}\text { Yao et al. } \\
\text { (2021) }\end{array}$ \\
\hline & Hydroxytyrosol & $\begin{array}{l}\text { Olea europaea L., Oleaceae } \\
\text { Hoffmanns. and Link }\end{array}$ & In vitro, TNF-amice chondrocytes & $\begin{array}{l}0,12.5,25,50,100,200 \text { and } \\
400 \mu \mathrm{M} \text {, last for } 24 \mathrm{~h}\end{array}$ & $50 \mu \mathrm{M}$ & SIRT6 pathway & $\begin{array}{l}\text { Zhi et al. } \\
\text { (2018) }\end{array}$ \\
\hline & & & $\begin{array}{l}\text { In vitro, } \mathrm{H}_{2} \mathrm{O}_{2} \text { induced } \mathrm{OA} \text { human } \\
\text { chondrocytes }\end{array}$ & $100 \mu \mathrm{M}$ for $30 \mathrm{~min}$ & $100 \mu \mathrm{M}$ & SIRT1 pathway & $\begin{array}{l}\text { Cetrullo et al. } \\
\text { (2016) }\end{array}$ \\
\hline & Resveratrol & $\begin{array}{l}\text { Vitis vinifera L., Vitaceae } \\
\text { Juss }\end{array}$ & $\begin{array}{l}\text { In vitro, DMM surgery mice } \\
\text { chondrocytes } \\
\text { In vivo, DMM surgery mice }\end{array}$ & $\begin{array}{l}125 \mathrm{mg} \text { via intra-articular } \\
\text { injection for } 8 \mathrm{w}\end{array}$ & $125 \mathrm{mg}$ & $\begin{array}{l}\text { HIF-1 } \alpha \text {-dependent AMPK and } \\
\text { mTOR signaling }\end{array}$ & $\begin{array}{l}\text { Qin et al. } \\
(2017)\end{array}$ \\
\hline & Butein & $\begin{array}{l}\text { Butea monosperma (Lam.) } \\
\text { Kuntze, Fabaceae Lindl }\end{array}$ & $\begin{array}{l}\text { In vitro, IL-1 } \beta \text { induced TKA surgery } \\
\text { human chondrocytes }\end{array}$ & $\begin{array}{l}0.6 \mu \mathrm{g} / \mathrm{ml}-10 \mu \mathrm{gg} / \mathrm{ml} \text { (or } \\
2.25-36 \mu \mathrm{M} \text { ) for } 24 \mathrm{~h}\end{array}$ & $10 \mu \mathrm{g} / \mathrm{ml}(36 \mu \mathrm{M})$ & $\begin{array}{l}\text { AMPK/TSC2/ULK1/mTOR } \\
\text { pathway }\end{array}$ & $\begin{array}{l}\text { Ansari et al. } \\
\text { (2018a) }\end{array}$ \\
\hline & Mangiferin & $\begin{array}{l}\text { Mangifera indica L., } \\
\text { Anacardiaceae R.Br }\end{array}$ & In vivo, DMM surgery mice & $\begin{array}{l}10 \mathrm{mg} / \mathrm{kg} \text { once a day for } \\
8 \text { weeks }\end{array}$ & $10 \mathrm{mg} / \mathrm{kg}$ & AMPK signaling pathway & $\begin{array}{l}\text { Li et al. } \\
(2019 b)\end{array}$ \\
\hline & & & $\begin{array}{l}\text { In vitro, TBHP-induced } \\
\text { chondrocytes from mice }\end{array}$ & $0,5,10,50,100,200 \mu \mathrm{M}$ & $100 \mu \mathrm{M}$ & & \\
\hline & Delphinidin & $\begin{array}{l}\text { Aristotelia chilensis (Molina) } \\
\text { Stuntz, Elaeocarpaceae } \\
\text { Juss }\end{array}$ & $\begin{array}{l}\text { In vitro, } \mathrm{H}_{2} \mathrm{O}_{2} \text { induced } \mathrm{C} 28 / 12 \\
\text { human chondrocytes }\end{array}$ & $10-75 \mu \mathrm{M}$ & $40 \mu \mathrm{M}$ & Nrf2 and NF-kB were activated & $\begin{array}{l}\text { Lee et al. } \\
(2020)\end{array}$ \\
\hline & Punicalagin & $\begin{array}{l}\text { Punica granatum L., } \\
\text { Lythraceae J.St.-Hil }\end{array}$ & $\begin{array}{l}\text { In vitro, TBHP induced mice } \\
\text { chondrocytes }\end{array}$ & $0-50 \mu \mathrm{g} / \mathrm{ml}$ & $50 \mu \mathrm{g} / \mathrm{ml}$ & $\begin{array}{l}\text { Autophagic flux in chondrocytes } \\
\text { after TBHP treatment recovered }\end{array}$ & $\begin{array}{l}\text { Kong et al. } \\
(2020)\end{array}$ \\
\hline & & & In vivo, DMM surgery mice & $\begin{array}{l}20 \mathrm{mg} / \mathrm{kg} \text { via oral } \\
\text { administration each day for } \\
8 \text { weeks }\end{array}$ & $20 \mathrm{mg} / \mathrm{kg}$ & & \\
\hline & & & $\begin{array}{l}\text { In vitro, rats chondrocytes } \\
\text { In vivo, Rats with cut anterior } \\
\text { cruciate ligament, medial collateral } \\
\text { ligament and medial meniscus }\end{array}$ & $\begin{array}{l}0,25,50 \text { and } 100 \mu \mathrm{M} \\
10 \mathrm{mg} / \mathrm{kg} \text { via oral } \\
\text { administration for } 12 \text { weeks }\end{array}$ & $\begin{array}{l}50 \mu \mathrm{M} \\
10 \mathrm{mg} / \mathrm{kg}\end{array}$ & Foxo1/Prg4/HIF3 $\alpha$ axis & $\begin{array}{l}\text { Liu et al. } \\
\text { (2021) }\end{array}$ \\
\hline & $\begin{array}{l}\text { (-)Epigallocatechin 3- } \\
\text { Gallate }\end{array}$ & $\begin{array}{l}\text { Camellia sinensis (L.) } \\
\text { Kuntze, Theaceae Mirb. ex } \\
\text { Ker Gawl }\end{array}$ & In vivo, ACLT surgery rats & $\begin{array}{l}10 \mu \mathrm{M} \text { EGCG by intra-articular } \\
\text { injection once every } 3 \text { days for } \\
5 \text { weeks }\end{array}$ & $10 \mu \mathrm{M}$ & $\begin{array}{l}\text { mTOR expression was reduced } \\
\text { and LC3, Beclin-1 and p62 } \\
\text { expression were increased }\end{array}$ & $\begin{array}{l}\text { Huang et al. } \\
(2020)\end{array}$ \\
\hline & Chlorogenic acid & $\begin{array}{l}\text { Bauhinia macrantha Oliv., } \\
\text { Fabaceae Lindl }\end{array}$ & $\begin{array}{l}\text { In vitro, Human chondrocyte C28/12 } \\
\text { cells }\end{array}$ & $0,50,100,200,250,400 \mu \mathrm{M}$ & $250 \mu \mathrm{M}$ & $\begin{array}{l}\text { Antioxidant response proteins Nrf2 } \\
\text { and NF-kB were increased }\end{array}$ & $\begin{array}{l}\text { Zada et al. } \\
\text { (2021) }\end{array}$ \\
\hline \multirow[t]{2}{*}{ Flavonoids } & Icariin & $\begin{array}{l}\text { Epimedium sagittatum } \\
\text { (Sieb. and Zucc.) Maxim., }\end{array}$ & $\begin{array}{l}\text { In vitro, TNF- } \alpha \text { induced rats } \\
\text { chondrocytes }\end{array}$ & $0,3,5,7,10$, and $20 \mu \mathrm{M}$ & $10 \mu \mathrm{M}$ & $\begin{array}{l}\text { p65 nuclear translocation and } I_{k} B a \\
\text { protein degradation were inhibited }\end{array}$ & Mi et al. (2018) \\
\hline & & Berberidaceae Juss & In vivo, ACTL surgery rats & $\begin{array}{l}20,40 \text {, or } 80 \mathrm{mg} / \mathrm{kg} / \text { day by } \\
\text { intraperitoneal injection for } 4 \\
\text { consecutive weeks }\end{array}$ & $20 \mathrm{mg} / \mathrm{kg}$ & PISK/AKT/mTOR pathway & $\begin{array}{l}\text { Tang et al. } \\
\text { (2021) }\end{array}$ \\
\hline
\end{tabular}


TABLE 1 | (Continued) Phytochemicals improve cartilage homeostasis via mediated autophagy against OA in vitro/in vivo.

\begin{tabular}{|c|c|c|c|c|c|c|c|}
\hline & Phytochemical & Plant species, family & Model & Dosage range & $\begin{array}{c}\text { Active } \\
\text { concentration }\end{array}$ & Signal pathways/Mechanisms & References \\
\hline & & & $\begin{array}{l}\text { In vitro, chondrocytes from ACTL } \\
\text { surgery rats }\end{array}$ & $1-100 \mu \mathrm{M}$ & $80 \mu \mathrm{M}$ & & \\
\hline & Baicalin & $\begin{array}{l}\text { Scutellaria baicalensis } \\
\text { Georgi, Lamiaceae Martinov }\end{array}$ & $\begin{array}{l}\text { In vitro, IL-1 } \beta \text {-induced } \\
\text { chondrocytes from TKA surgery OA } \\
\text { patients }\end{array}$ & $20 \mu \mathrm{M}$ & $20 \mu \mathrm{M}$ & $\begin{array}{l}\text { miR-766-3p level was upregulated } \\
\text { and AIFM1 expression was } \\
\text { decreased }\end{array}$ & Li et al. (2020) \\
\hline & Glabridin & $\begin{array}{l}\text { Glycyrrhiza glabra L., } \\
\text { Fabaceae Lindl }\end{array}$ & $\begin{array}{l}\text { In vitro, human OA chondrocytes } \\
\text { In vivo, ACLT surgery rats }\end{array}$ & $\begin{array}{l}0.01-10 \mu \mathrm{M} \\
1,5 \text {, and } 10 \mathrm{mg} / \mathrm{kg} \text { for } 4 \text { or } \\
8 \text { weeks }\end{array}$ & $\begin{array}{l}1 \mu \mathrm{M} \\
1 \mathrm{mg} / \mathrm{kg}\end{array}$ & mTOR pathway & $\begin{array}{l}\text { Dai et al. } \\
\text { (2021b) }\end{array}$ \\
\hline & Rhoifolin & $\begin{array}{l}\text { Rhus succedanea } \mathrm{L} \text {, } \\
\text { Anacardiaceae } \mathrm{R} \cdot \mathrm{Br}\end{array}$ & $\begin{array}{l}\text { In vitro, } \mathrm{IL}-1 \beta \text { induced rats } \\
\text { chondrocytes }\end{array}$ & $0,5,10$, and $20 \mu \mathrm{M}$ & & $\begin{array}{l}\text { P38/JNK pathway and PI3K/AKT/ } \\
\text { mTOR pathway }\end{array}$ & $\begin{array}{l}\text { Yan et al. } \\
\text { (2021) }\end{array}$ \\
\hline & & & In vivo, ACLT surgery rats & $\begin{array}{l}20 \mu \mathrm{M} \text { intra-articular injection } \\
\text { weekly for } 8 \text { weeks }\end{array}$ & $20 \mu \mathrm{M}$ & & \\
\hline & Eupatilin & $\begin{array}{l}\text { Artemisia absinthium L., } \\
\text { Asteraceae Bercht. and } \\
\text { J.Presl }\end{array}$ & $\begin{array}{l}\text { In vitro, IL- } 1 \beta \text { induced rats } \\
\text { chondrocytes }\end{array}$ & $0,25,50,100 \mu \mathrm{M}$ & $25 \mu \mathrm{M}$ & Senstrin2-dependent autophagy & $\begin{array}{l}\text { Lou et al. } \\
\text { (2019) }\end{array}$ \\
\hline & Sinensetin & $\begin{array}{l}\text { Citrus L., Phyllanthaceae } \\
\text { Martinov }\end{array}$ & $\begin{array}{l}\text { In vitro, TBHP induced mice } \\
\text { chondrocytes }\end{array}$ & $0,10,20,30,40$, and $50 \mu \mathrm{M}$ & $10 \mu \mathrm{M}$ & AMPK/mTOR signaling pathway & $\begin{array}{l}\text { Zhou et al. } \\
\text { (2021a) }\end{array}$ \\
\hline \multirow{5}{*}{ Terpenoids } & & & In vivo, DMM surgery mice & $50 \mathrm{mg} / \mathrm{kg}$ by gavage for $8 \mathrm{w}$ & $50 \mathrm{mg} / \mathrm{kg}$ & & \\
\hline & Morroniside & $\begin{array}{l}\text { Corni Fructus, Cornaceae } \\
\text { Bercht. and J.Presl }\end{array}$ & $\begin{array}{l}\text { In vitro, TKA surgery human } \\
\text { chondrocytes }\end{array}$ & $0,1,20,200 \mu \mathrm{M}$ & $20 \mu \mathrm{M}$ & $\mathrm{PI} 3 \mathrm{~K} / \mathrm{AKT} / \mathrm{mTOR}$ signal pathway & $\begin{array}{l}\text { Xiao et al. } \\
(2020)\end{array}$ \\
\hline & Lycopene & $\begin{array}{l}\text { Solanum lycopersicum L., } \\
\text { Solanaceae Juss }\end{array}$ & $\begin{array}{l}\text { In vitro, } \mathrm{H}_{2} \mathrm{O}_{2} \text { induced } \mathrm{SD} \text { rats } \\
\text { chondrocytes }\end{array}$ & $0.001-10 \mu \mathrm{M}$ & $0.1 \mu \mathrm{M}$ & MAPK and PI3K/Akt/NF-kB axis & $\begin{array}{l}\text { Wu et al. } \\
(2021)\end{array}$ \\
\hline & Celastrol & $\begin{array}{l}\text { Tripterygium wilfordii, } \\
\text { Celastraceae R.Br }\end{array}$ & $\begin{array}{l}\text { In vitro, IL-1 } \beta \text { induced SD rats } \\
\text { chondrocytes }\end{array}$ & $0-1.6 \mu \mathrm{M}$ & $0.2 \mu \mathrm{M}$ & $\begin{array}{l}\text { The expression of LC3-II and } \\
\text { Beclin-1 increased }\end{array}$ & $\begin{array}{l}\text { Feng et al. } \\
(2020)\end{array}$ \\
\hline & & & In vivo, ACLT surgery rats & $\begin{array}{l}0.5 \mathrm{mg} / \mathrm{kg}, 1 \mathrm{mg} / \mathrm{kg} \text { by } \\
\text { intraperitoneal injection } \\
\text { for } 12 \mathrm{w}\end{array}$ & $0.5 \mathrm{mg} / \mathrm{kg}$ & & \\
\hline \multirow[t]{3}{*}{ Coumarins } & Isoimperatorin & $\begin{array}{l}\text { Angelica dahurica, } \\
\text { Apiaceae Lindl }\end{array}$ & In vivo, DMM surgery mice & $\begin{array}{l}500 \mathrm{mg} / \mathrm{kg} \text { via oral admin- } \\
\text { istration for } 4 \mathrm{w}\end{array}$ & $500 \mathrm{mg} / \mathrm{kg}$ & mTORC1 pathway & $\begin{array}{l}\text { Ouyang et al. } \\
\text { (2017) }\end{array}$ \\
\hline & & & $\begin{array}{l}\text { In vitro, DMM surgery mice } \\
\text { chondrocytes }\end{array}$ & $1-100 \mathrm{mM}$ & $1 \mu \mathrm{M}$ & & \\
\hline & Isopsoralen & $\begin{array}{l}\text { Cullen corylifolium (L.) } \\
\text { Medik., Fabaceae Lindl }\end{array}$ & $\begin{array}{l}\text { In vitro, IL-1 } 1 \beta \text { induced rats } \\
\text { chondrocytes }\end{array}$ & $5,10,20$, and $40 \mu \mathrm{g} / \mathrm{ml}$ & $20 \mu \mathrm{g} / \mathrm{ml}$ & $\begin{array}{l}\text { LC3-II and LAMP-1 expression was } \\
\text { significantly increased, but p62/ } \\
\text { SQSTM1 expression was } \\
\text { significantly decreased }\end{array}$ & $\begin{array}{l}\text { Chen et al. } \\
\text { (2020b) }\end{array}$ \\
\hline \multirow[t]{2}{*}{ Saponin } & Astragaloside IV & $\begin{array}{l}\text { Astragalus mongholicus } \\
\text { Bunge, Fabaceae Lindl }\end{array}$ & $\begin{array}{l}\text { In vitro, IL-1 } \beta \text { induced TKA surgery } \\
\text { human chondrocytes }\end{array}$ & $50 \mu \mathrm{g} / \mathrm{ml}$ & $50 \mu \mathrm{g} / \mathrm{ml}$ & $\begin{array}{l}\text { Protein expression of LC3-1I/I was } \\
\text { increased and that of P62/SQSTM1 } \\
\text { was decreased }\end{array}$ & $\begin{array}{l}\text { Liu et al. } \\
(2017)\end{array}$ \\
\hline & Huzhangoside D & $\begin{array}{l}\text { Clematis graveolens Lindl., } \\
\text { Ranunculaceae Juss }\end{array}$ & In vivo, $\mathrm{ACLT}$ surgery rats & $\begin{array}{l}17,34,68 \mathrm{mg} / \mathrm{kg} \text { via } \\
\text { intraperitoneal injection daily } \\
\text { for } 4 \mathrm{~W}\end{array}$ & $17 \mathrm{mg} / \mathrm{kg}$ & AKT and mTOR signaling pathway & $\begin{array}{l}\text { Zhang et al. } \\
\text { (2021) }\end{array}$ \\
\hline \multirow[t]{2}{*}{$\begin{array}{l}\text { Small } \\
\text { molecules } \\
\text { compounds }\end{array}$} & $\beta$-ecdysterone & $\begin{array}{l}\text { Achyranthes bidentata, } \\
\text { Amaranthaceae Juss }\end{array}$ & $\begin{array}{l}\text { In vivo, MIA intraperitoneal injection } \\
\text { induced OA rats }\end{array}$ & $\begin{array}{l}0.6 \mathrm{mg} / \mathrm{kg}, 0.8 \mathrm{mg} / \mathrm{kg} \text {, and } \\
1 \mathrm{mg} / \mathrm{kg} \text { via subcutaneous } \\
\text { injection twice a week for } \\
4 \text { weeks }\end{array}$ & $0.6 \mathrm{mg} / \mathrm{kg}$ & PI3K/AKT/MTOR signal pathway & $\begin{array}{l}\text { Tang et al. } \\
(2020)\end{array}$ \\
\hline & & & $\begin{array}{l}\text { In vitro, DMM surgery mice } \\
\text { chondrocytes }\end{array}$ & $10,20,40 \mu \mathrm{M}$ & $10 \mu \mathrm{M}$ & & \\
\hline
\end{tabular}




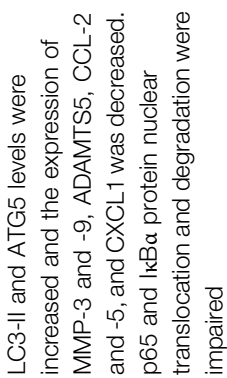

$\underset{\sum}{-}$

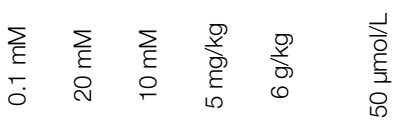
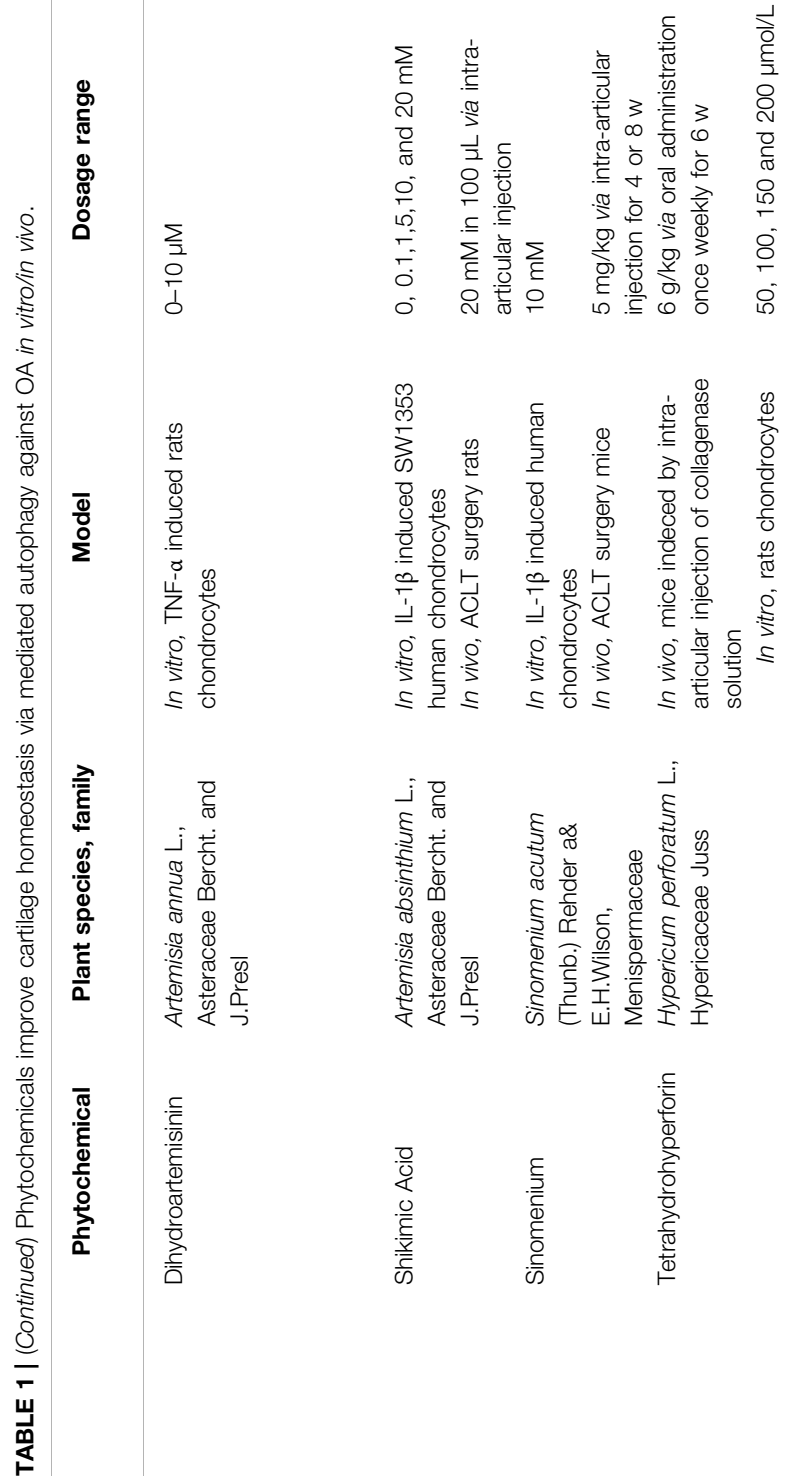
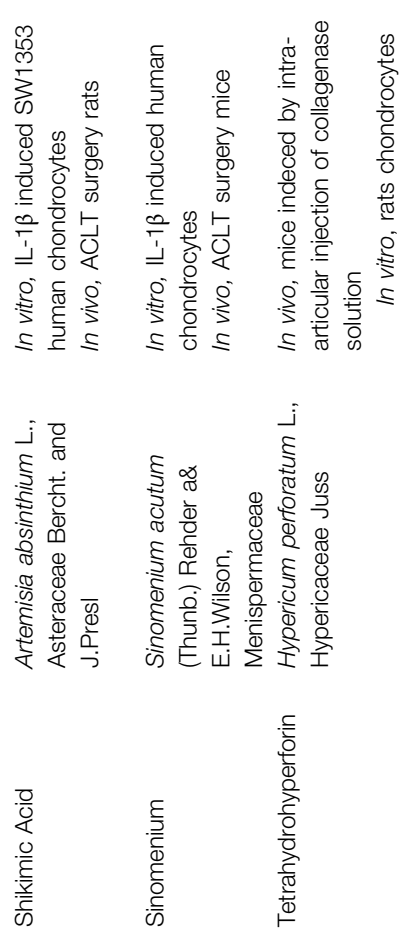

of autophagy activation is the conversion of microtubuleassociated protein 1A/1B-light chain 3 (LC3) from LC3-I to LC3-II, a lipidated form of the former protein that allows LC3-II to adhere to the phagocytic membrane during autophagosome formation and extension (Mizushima and Yoshimori, 2007). Under normal cellular conditions, most LC3 proteins are expressed as cytoplasmic LC3-I, which is converted to LC3-II upon autophagy activation by binding to diethanolamine phosphate (PE) and dispersing in the outer and inner membranes of autophagosomes, and this conversion is widely used as an indicator of autophagy activation (Jiang et al., 2016; Ansari et al., 2017). Autophagy deficiency or lack of autophagy activation induces apoptosis (Hara et al., 2006). It has been found that the expression of autophagy regulatory factors and autophagy-related proteins was observed to be downregulated in articular cartilage isolated from OA animals or humans, accompanied by increased chondrocyte apoptosis, suggesting that impaired autophagy is a contributing factor in the development of OA (Taniguchi et al., 2009; Caramés et al., 2010; Vinatier et al., 2018). In addition, the capacity of cells to degrade damaged components by activating autophagy is limited, and excessive oxidative stress can exceed the limits of autophagy, leading to a severe decrease in autophagic flux and impaired function, which can lead to cellular senescence and apoptosis, resulting in the progression of OA (Roca-Agujetas et al., 2019). In early stage of OA, autophagy in chondrocytes and cartilage tissue is confirmed by the upregulation of the autophagy-associated protein LC3. However, the transient activation of autophagy is shown to be only a compensatory response to cellular stress. In late stage of $\mathrm{OA}$, the compensatory response fails to offset oxidative stress and causes structural cellular damage accompanied by inhibition of autophagy (Portal-Núñez et al., 2016; Tang et al., 2020). Nevertheless, the activation of autophagy during the early development of $\mathrm{OA}$ is still positive for chondrocyte survival. When autophagy is activated, damaged mitochondria can be removed and intracellular ROS are reduced, protecting chondrocytes from the negative effects of OA. There is evidence that enhanced autophagy in chondrocytes can slow the progression of OA by affecting intracellular metabolic activity (Caramés et al., 2010; Barranco, 2015; Caramés et al., 2015; Luo et al., 2019). Consequently, autophagy plays an irreplaceable role in protecting chondrocytes from oxidative stress (Ansari et al., 2018b). Figure 1 provides an overview of the mechanism of maintaining cartilage homeostasis through regulation of autophagy.

\section{PHYTOCHEMICALS FOR THE TREATMENT OF OA BY PROMOTING AUTOPHAGY}

Phytochemicals from traditional medicinal plants are inexpensive and widely available, and can exert anti-inflammatory and antioxidant effects with good pharmacological activity. In recent years, various phytochemicals have been used in the prevention and treatment of various diseases by modulating autophagic targets, such as cardiovascular diseases and cancer 


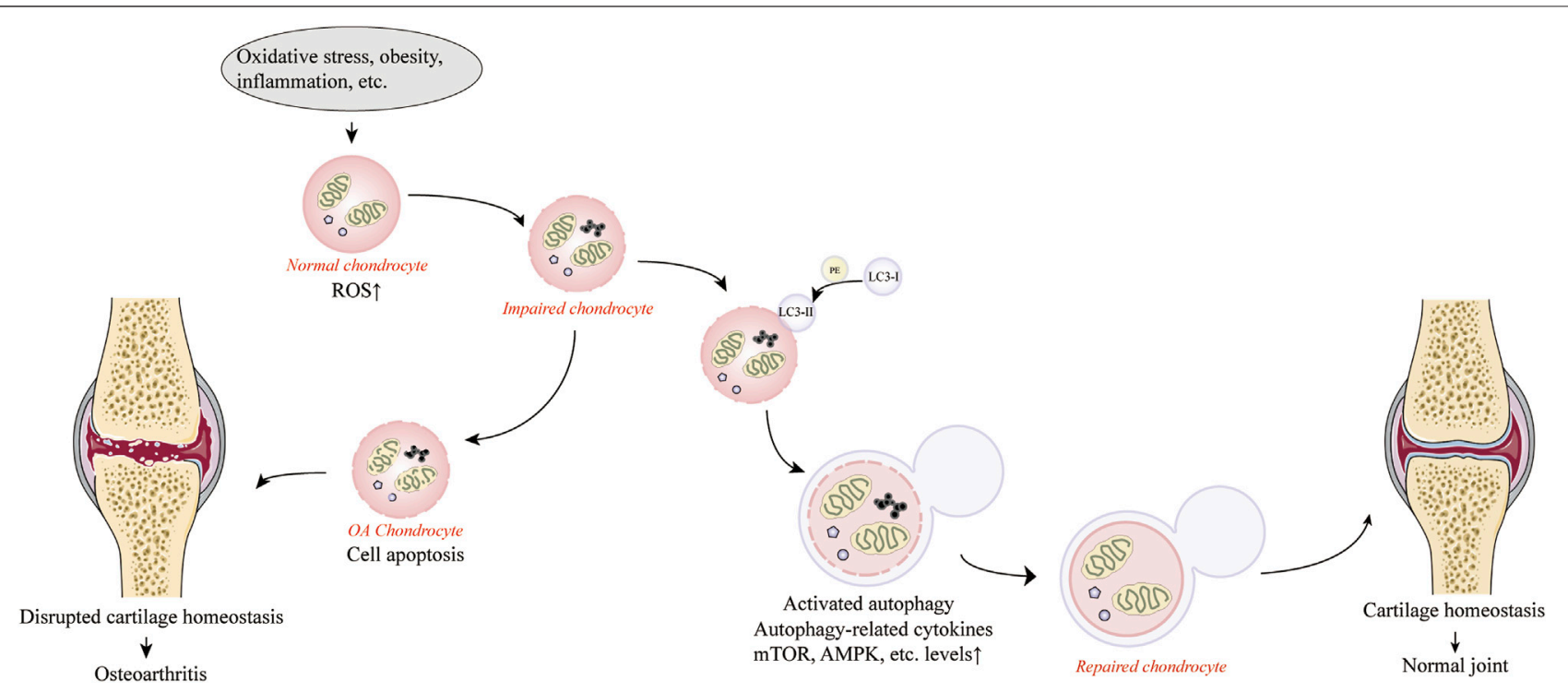

FIGURE 1 | Activation of autophagy against osteoarthritis by maintaining cartilage homeostasis. Produced using Servier Medical Art (smart.servier.com).

(Hong et al., 2020; Li et al., 2020; Luo et al., 2020). Therefore, it is expected that phytochemicals derived from medicinal plants may retard the development of OA by mediating autophagy. There is increasing evidence that phytochemicals can also target autophagic pathways to function as complementary and alternative drugs for OA treatment, and their mechanisms related to the treatment of $\mathrm{OA}$ through the autophagic pathway are receiving increasing attention (Hu et al., 2020; Liu et al., 2020; Yu et al., 2021). In this review, we have selected phytochemicals that have the potential to activate autophagic pathways mediating cartilage homeostasis against $\mathrm{OA}$ in recent years. The anti-osteoarthritis activity of these phytochemicals and their mechanistic effects are described in the following sections. Figure 2 illustrates the autophagic pathways of phytochemicals against $\mathrm{OA}$.

\subsection{Polyphenols}

Polyphenols, a large family of naturally occurring organic compounds characterized by multiples of phenol units, are widely distributed in numerous plants including vegetables, fruits, and botanical drugs (Salucci et al., 2017). It has been found that polyphenols are able to treat oxidative stress, inflammation and neurological diseases by mediating the autophagic pathway, and it has also been shown that polyphenols help to fight against OA (Varela-Eirín et al., 2020; Valsamidou et al., 2021). Here, we will summarize the existing scientific evidence gathered from in vitro and in vivo studies which support the beneficial effects of polyphenols on ameliorating OA by mediating the autophagic pathways.

\subsubsection{Curcumin}

Curcumin, a polyphenol derived from Curcuma longa L., has anti-inflammatory and antioxidant properties and functions as an anti-inflammatory therapeutic agent in Chinese medicine (Goel et al., 2008). Several studies have found that curcumin can treat OA by mediating autophagy-related pathways and thus improving the status of chondrocytes in an in vitro OA model. Li et al. treated mice primary chondrocytes with curcumin and observed that curcumin reduced the expression of autophagy markers LC3-II and Beclin-1 through suppressing mitogenactivated protein kinase/extracellular signal-regulated kinase 1/ 2 (MAPK/ERK1/2) signaling pathway, thereby inhibiting interleukin-1beta (IL-1 $\beta$ )-induced chondrocyte apoptosis and activation of cysteine aspartate protease-3 (Caspase-3), exerting its anti-inflammatory and anti-apoptotic effects ( $\mathrm{Li}$ et al., 2017a). Similarly, Chen et al. also found that the curcumin pretreatment reduced IL- $1 \beta$-induced apoptosis in rat primary chondrocytes through activation of autophagy and inhibition of nuclear factor- $\kappa \mathrm{b}(\mathrm{NF}-\mathrm{\kappa B})$ signaling pathway (Chen et al., 2021). In addition, curcumin has been found to activate autophagy and thus improve the function of chondrocytes in vivo models of OA. By establishing aging spontaneous $\mathrm{OA}$ and the destabilization of the medial meniscus (DMM) surgery-induced OA models in mice, Zhang et al. found that curcumin treatment promoted autophagy by suppressing the protein kinase $\mathrm{B} /$ mechanistic target of rapamycin kinase (AKT/mTOR) signaling pathway enhanced autophagy and reduced apoptosis and cartilage loss (Zhang et al., 2018a). Yao et al. established a rat model of OA by feeding a high-fat diet and injected curcumin into the knee joints of OA rats and found that the chondroprotective effect of curcumin may be achieved in part through inhibition of AKT/mTOR pathway autophagy (Yao et al., 2021). Besides, there is a study confirming that curcumin has been used clinically and has been shown to improve pain in patients with mild to moderate OA. But the limitations of curcumin being used in the clinic are mainly due to its low bioavailability and unstable metabolism in the body (Panahi et al., 2014). Curcumin showed low absorption and poor stability in 


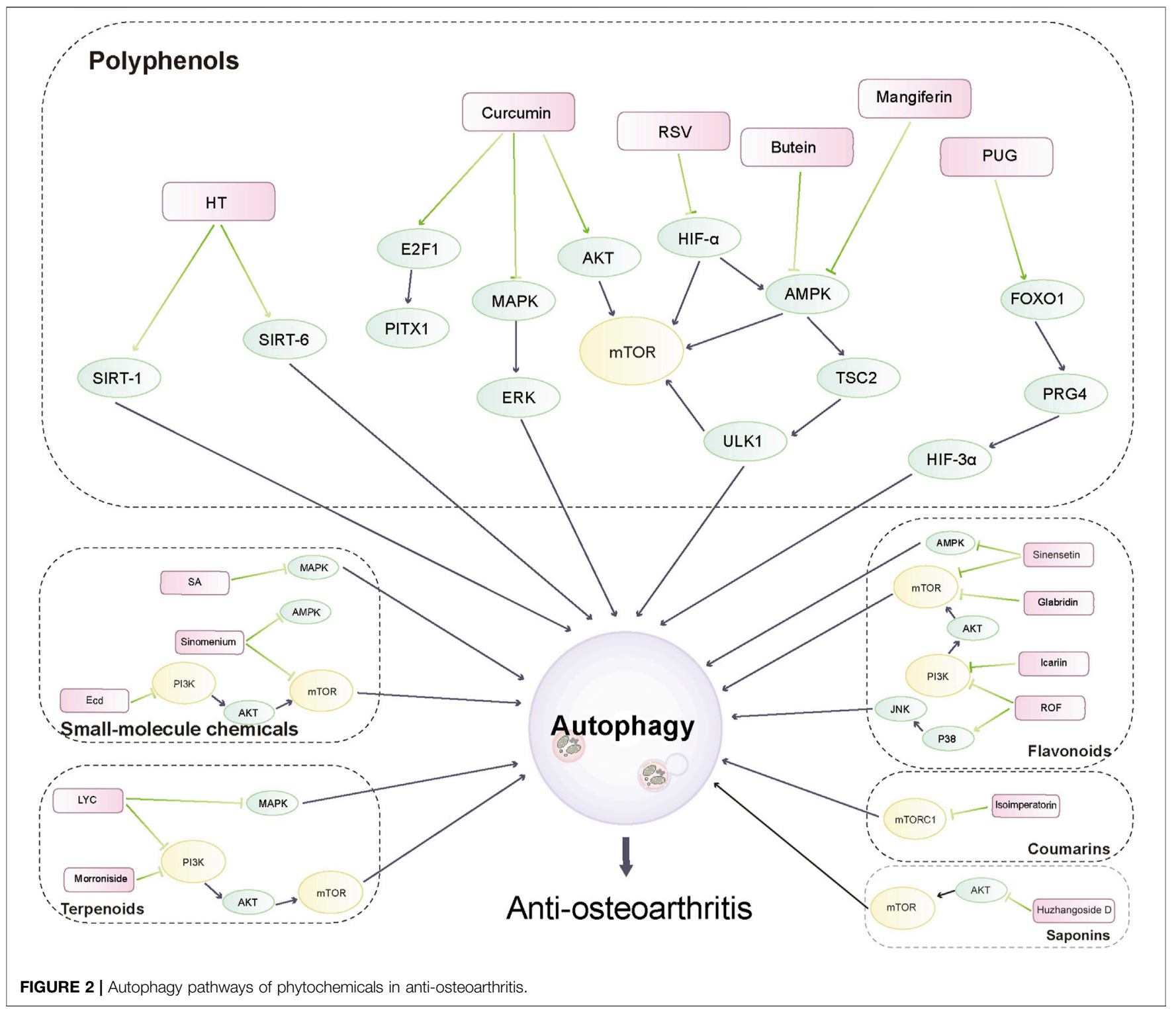

vivo and in vitro environments (T1/2 $<5 \mathrm{~min} ; \mathrm{F}<1 \%$ ) (Yang et al., 2007). In addition, its solubility in water is limited, with the maximum solubility in $\mathrm{pH} 5.0$ aqueous buffer only $11 \mathrm{ng} / \mathrm{ml}$ (Chen et al., 2015). It showed that orally administered curcumin at a dose of $1 \mathrm{~g} / \mathrm{kg}$ only had $0.5 \mu \mathrm{g} / \mathrm{ml}$ maximum serum concentration, indicating only $1 \%$ oral bioavailability (Maiti et al., 2007). Current strategies to improve the bioavailability of curcumin are mainly to change the delivery method of curcumin, to modify it chemically or to combine it with other drugs (Prasad et al., 2014). In conclusion, curcumin, as an active ingredient derived from a natural drug that promotes autophagy, may have great promise in the treatment of $\mathrm{OA}$ through autophagy-mediated cartilage homeostasis.

\subsubsection{Hydroxytyrosol}

Olive oil is the main source of fat in the Mediterranean diet (Granados-Principal et al., 2010). Studies on animal models of arthritis (Musumeci et al., 2013; Rosillo et al., 2014; Silva et al., 2015) and some preliminary trials (Bohlooli et al., 2012; Takeda et al., 2013) suggest that treatment with olive oil or olive phenolrich extracts may be beneficial for patients with OA. Hydroxytyrosol (HT), the main phenolic in Olea europaea L, has been of interest for its potent antioxidant capacity, and studies have been conducted to identify the health benefits of HT in the prevention or treatment of cardiovascular disease, diabetes and cancer (Granados-Principal et al., 2010; Hu et al., 2014). Relevant in vitro experiments revealed that $\mathrm{HT}$ can regulate autophagy and thus improve chondrocyte function. Cetrullo et al. found experimentally that $\mathrm{HT}$ increases autophagy markers through the induction of the Sirtuin-1 (SIRT-1) pathway, thus protecting human primary chondrocytes from DNA damage and cell death due to oxidative stress increased by hydrogen peroxide (Cetrullo et al., 2016). It has been shown that HT increased autophagy in chondrocytes and preosteoblasts and protected them from cell 
death and oxidative damage (Aparicio-Soto et al., 2015). The results of Zhi et al. showed that HT may promote chondrocyte autophagy through Sirtuin-6 (SIRT6) and decreased Tumour Necrosis Factor alpha (TNF- $\alpha$ )-induced interleukin-1 $\beta$ (IL-1 $\beta$ ) and interleukin-6 (IL-6) levels, thus protecting chondrocytes from TNF- $\alpha$-induced inflammatory response and oxidative stress-induced DNA damage and cell death (Zhi et al., 2018). Such evidence suggests the potential of HT in preventing chondrocytes from being affected by OA through the relevant autophagic pathway. HT, a hydrophilic phenolic antioxidant, has broad potential for mediating autophagy in the treatment of OA (Cornwell and Ma, 2008).

\subsubsection{Resveratrol}

Resveratrol (RSV), an active substance derived from Vitis vinifera $\mathrm{L}$, has long been used in traditional Chinese medicine, and some studies have demonstrated that RSV inhibits the inflammatory response to $\mathrm{OA}$ in both in vivo and in vitro models (Zhang et al., 2020). Recently, in vitro and in vivo studies have also revealed that RSV can improve chondrocyte function by mediating autophagyrelated pathways, thereby delaying OA progression. Qin et al. demonstrated experimentally that intra-articular injections of RSV upregulated the expression of hypoxia-inducible factor-1 alpha (HIF-1 $\alpha$ ) and hypoxia-inducible factor-2 alpha (HIF-2 $\alpha$ ) by up-regulating the AMP-activated protein kinase (AMPK)/ mTOR signaling pathway, thereby promoting chondrocyte autophagy and delayed the degeneration of articular cartilage in a DMM-induced OA model (Qin et al., 2017). Additionally, RSV has been used clinically and has been shown to improve pain conditions and knee function in patients with OA (Nguyen et al., 2017; Wong et al., 2017; Hussain et al., 2018). It is notable that there are some limitations to the utilization of resveratrol. First, the solubility of resveratrol is relatively low, $0.05 \mathrm{mg} / \mathrm{ml}$ when dissolved in water, and in addition, resveratrol is chemically unstable when exposed to the intrinsic enzymatic and $\mathrm{PH}$ environment of the gastric and intestinal tract, which reduces the low bioavailability after oral administration (Francioso et al., 2014; Robinson et al., 2015). However, RSV still has the potential to improve chondrocyte homeostasis in OA progression by mediating autophagy, thus emerging as a new therapeutic approach for OA.

\subsubsection{Butein}

Butein is a polyphenol derived primarily from Butea monosperma (Lam.) Kuntze. Plant extracts containing butein are traditionally used in Ayurvedic and Unani India as well as in Chinese medical systems to treat various human ailments. (Wang et al., 2014). Butein has been shown to inhibit the pro-inflammatory effects of IL-1 $\beta$ on chondrocytes (Zheng et al., 2017). Ansari treated IL-1 $\beta$ induced human chondrocytes with butein and showed that butein activated autophagy through suppressing the AMPK/ Tuberous sclerosis complex 2 (TSC2)/Unc-51-like kinase 1 (ULK1)/mTOR pathway and inhibited IL-6 expression in human chondrocytes, thereby protecting chondrocytes from OA (Ansari et al., 2018a). It has been found that Butein binds to human serum albumin (HSA) through hydrophobic interaction, thus successfully penetrating into the cell membrane to exert pharmacological effects (Padmavathi et al., 2017). As a potential therapeutic agent to improve chondrocyte homeostasis and thus treat and/or prevent OA through autophagy, butein deserves further investigation.

\subsubsection{Mangiferin}

Mangiferin, a natural polyphenol derived mainly from Mangifera indica $\mathrm{L}$., is able to exert anti-inflammatory and antioxidant effects (Sellés et al., 2015), while it has been suggested that mangiferin may promote bone repair in endochondral osteogenesis by activating autophagy (Bai et al., 2018). Li et al. applied mangiferin treatment to reverse oxidative stress induced by tert-butyl hydroperoxide (TBHP) and alleviate chondrocyte apoptosis and ECM degradation in an in vitro experiment. In vivo experiments likewise confirmed that mangiferin could exert therapeutic effects on DMM-induced OA mice by activating autophagy. Their findings showed that mangiferin decreased mTOR activity and promoted phosphorylation of AMPK to activate autophagy in a time- and dose-dependent manner ( $\mathrm{Li}$ et al., 2019b). This evidence demonstrates the ability of mangiferin to mitigate chondrocyte apoptosis and ECM degradation by regulating the autophagic pathway, thus exerting an anti-osteoarthritic effect. A clinical study found the concentration of mangiferin in plasma reached $38.64 \pm 6.75 \mathrm{ng} /$ $\mathrm{ml}$ approximately $1 \mathrm{~h}$ after oral administration of $0.9 \mathrm{~g}$ of mangiferin, with an apparent elimination half-life (t1/2) of $7.85 \pm 1.72 \mathrm{~h}$, further demonstrating its potential application in clinically mediated autophagy for the treatment of $\mathrm{OA}$ (Hou et al., 2012).

\subsubsection{Delphinidin}

The natural compound anthocyanins extracted from Aristotelia chilensis (Molina) Stuntz are used to treat OA and several diseases (Kong et al., 2003). Among the various anthocyanins, delphinidin is a special class of polyphenols that protects chondrocytes and inhibits the progression of $\mathrm{OA}$ by mediating relevant cellular pathways against oxidative stress (Haseeb et al., 2013). Delphinidin has been reported to inhibit IL-1-induced matrix metalloproteinases (MMPs) expression in human articular chondrocytes via suppressing NF- $\kappa B$ and ERK/MAPK pathways (Wongwichai et al., 2019). Lee et al. applied delphinidin to hydrogen peroxide $\left(\mathrm{H}_{2} \mathrm{O}_{2}\right)$-treated human chondrocytes and found that delphinidin could activate autophagy by up-regulating nuclear factor erythroid 2-related factor 2 (NRF2) and NF-kB pathways to protect chondrocytes from oxidative stress generated by $\mathrm{H} 2 \mathrm{O} 2$ (Lee et al., 2020). Therefore, delphinidin may protect chondrocytes by inducing autophagy and thus stop the progression of OA, providing a new idea for the treatment of OA. The high hydrophilicity and instability of delphinidin may restrict its use in clinical practice, so it requires strategies to be developed to increase its bioavailability (Legeay et al., 2019).

\subsubsection{Punicalagin}

Punicalagin (PUG) is a hydrolyzable polyphenol extracted from Punica granatum $\mathrm{L}$. with a wide range of biological activities and cytoprotective effects (Yan et al., 2016; Foroutanfar et al., 2020). 
PUG has been reported to play a protective role in inhibiting apoptosis, and related studies have also shown that pomegranate glucoside is beneficial in the treatment of OA (Yu et al., 2019; Foroutanfar et al., 2020). Both in vivo and in vitro studies have shown that PUG can exert anti-osteoarthritic effects through activation of autophagy. Liu et al. found that PUG promotes autophagy through the forkhead box O1/proteoglycan 4 (FOXO1/Prg4)/HIF3 $\alpha$ axis, inhibits inflammation and extracellular matrix degradation, and attenuates inflammatory damage caused by lipopolysaccharide (LPS) in rat chondrocytes (Liu et al., 2021). In addition, Kong injected PUG in a mouse DMM model and showed that PUG increased antioxidant enzymes and reduced the degradation of apoptotic proteins and ECM by mediating autophagy, thus effectively stopping the progression (Kong et al., 2020). Although preclinical studies have shown that PUG can reduces chondrocyte apoptosis and ECM degradation through mediating autophagy, its solubility is low and insufficient for effective use after oral administration, which greatly limits its clinical application (Cerdá et al., 2005). However, the bioavailability of PUG can be promoted using micronization techniques therefore PUG has the potential to fight OA by mediating autophagy, but further experimental confirmation is needed (Nyamba et al., 2021).

\subsection{8 (-)-Epigallocatechin 3-Gallate}

(-)-Epigallocatechin gallate (EGCG) is the most abundant bioactive polyphenol in Camellia sinensis (L.) Kuntze and has been shown to have anti-inflammatory and antioxidant effects (Luk et al., 2020). Related in vitro experiment found EGCG can attenuate extracellular matrix degradation and inflammation by inhibiting MMPs and TNF- $\alpha$ activation (Rasheed et al., 2009). In addition, Huang et al. observed that intra-articular injection of EGCG reduced cartilage degradation in an anterior cruciate ligament transection (ACLT)-induced OA rat model by regulating the expression levels of autophagy-related marker proteins, namely, decreasing mTOR expression and enhancing LC3, beclin-1, and p62 expression, thereby reducing chondrocyte inflammation and apoptosis (Huang et al., 2020). It has been shown that there is no toxicity in rats consuming up to $500 \mathrm{mg} / \mathrm{kg} /$ day doses of EGCG dietary (Isbrucker et al., 2006). And the bioavailability of EGCG at a dose of $800 \mathrm{mg} /$ day showed a significant increase in healthy participants compared to a dose of $400 \mathrm{mg} /$ day (Chow et al., 2003). Therefore, EGCG may be an alternative treatment for OA because of its high bioavailability and its ability to improve chondrocyte apoptosis and cartilage degeneration in $\mathrm{OA}$ rat models.

\subsubsection{Chlorogenic Acid}

Chlorogenic acid (CGA) is a natural polyphenolic compound from Bauhinia macrantha Oliv. with antioxidant properties that have been found to protect against oxidative stress by activating multiple signaling pathways in chondrocytes (Hoelzl et al., 2010; Chen et al., 2011). Zada et al. found that CGA protects against $\mathrm{H} 2 \mathrm{O} 2$-induced oxidative stress by mediating autophagy while regulating antioxidant pathways such as NRF2 and NF- $\kappa B$ pathways, thereby protecting human chondrocytes from apoptosis and slow down the progression of OA (Zada et al.,
2021). A study reported that the apparent bioavailability of oral CGA in rats was 27-33\% (Farah et al., 2008). These results suggest that CGA can be used for drug development in OA by modulating autophagy for targeted treatment of OA.

\subsection{Flavonoids}

In recent years, researches have confirmed the beneficial effects of flavonoids to health, including their use in conditions related to autophagy, such as neurodegenerative diseases (Dai et al., 2021a; Pérez-Arancibia et al., 2021). A large number of experiments have shown that flavonoids and its derivatives can improve chondrocytes and thus combat against OA, which makes it possible to apply flavonoids in clinical studies (Basu et al., 2018; Ansari et al., 2020).

\subsubsection{Icariin}

Icariin, a flavonoid compound extracted from Epimedium sagittatum (Sieb and Zucc.) Maxim., has been shown to slow down the progression of OA by inhibiting the NF- $\kappa B$ pathway to attenuate the inflammatory response of chondrocytes (Hua et al., 2018) and by inhibiting the expression of MMP-13 and proinflammatory cytokines in chondrocytes (Zeng et al., 2014; Pan et al., 2017a; Sun et al., 2018). Related in vivo and in vitro experiments revealed its ability to protect chondrocytes from $\mathrm{OA}$ by activating autophagy. The results of $\mathrm{Mi}$ et al. showed that icariin protects chondrocytes from OA by inhibiting TNF$\alpha$-induced NF- $\kappa B$ signaling pathway to activate autophagy and significantly reduce apoptotic markers. In addition, icariin exerted the same effect as the Pyrrolidinedithiocarbamic acid (PDTC, NF- $\mathrm{BB}$ inhibitor) control, but it exerted a better antiinflammatory effect in inhibiting the activation of $N F-\kappa B$ signaling pathway (Mi et al., 2018). Tang et al. administered icariin intraperitoneally to DMM surgery induced OA rats and found that it attenuated $\mathrm{OA}$ in a dose-dependent manner by downregulating phosphatidylinositol 3-kinase (PI3K)/AKT/ mTOR signaling to activate autophagy in chondrocytes (Tang et al., 2021). Icariin has a low bioavailability due to its poor absorption, which poses additional limitations to its clinical application (Li et al., 2015). However, it has been found that the bioavailability of icariin can be improved by pharmacological methods (Zhang et al., 2012). Therefore, the studies on the activation of autophagy to maintain the homeostasis of chondrocytes by icariin are of guidance for the prevention and treatment of OA.

\subsubsection{Baicalin}

Baicalin, a principal flavonoid extracted from roots of Scutellaria baicalensis Georgi, has a wide range of biological activities such as anti-inflammatory and antioxidant (Wang et al., 2007; Lee et al., 2015), and some studies have shown that baicalin plays a role in improving OA progression (Pan et al., 2017b; Yang et al., 2018). $\mathrm{Li}$ et al. used baicalin to treat IL- $1 \beta$-treated human OA chondrocytes, and the results showed that baicalin increased the promotion of autophagy flux and attenuated IL-1 $\beta$ induced chondrocyte apoptosis and ECM degradation ( $\mathrm{Li}$ et al., 2020). However, the bioavailability of baicalin was found to be very low $(2.2 \%)$, therefore, how to improve the 
bioavailability of baicalin is still a problem (Xing et al., 2005). Nevertheless, it is undeniable that baicalin is promising in regulating the autophagic pathway against chondrocyte apoptosis and endochondral homeostasis against OA.

\subsubsection{Glabridin}

Glabridin is a flavonoid derived from Glycyrrhiza glabra L. that exerts powerful antioxidant effects by removing free radicals and has been found to be comparable to vitamin $\mathrm{E}$ in terms of its antioxidant capacity (Fuhrman et al., 2000; Simmler et al., 2013). It has been used to prevent and treat pathological changes associated with free radical oxidation, such as cellular senescence (Veratti et al., 2011). In addition, glabridin has been found to enhance the function of osteoblasts thereby preventing osteoporosis and various bone and joint diseases (Choi, 2011). Dai et al. found a significant increase in LC3-II levels in human chondrocytes after the administration of glabridin, suggesting that it could protect them from oxidative stress, apoptosis by enhancing autophagy. In vivo experiments revealed that glabridin could activate autophagy, which is to reduce mTOR expression, and increase LC3-II levels attenuated ACLT-induced apoptosis in OA rats, thereby delaying their cartilage degeneration (Dai et al., 2021b). The clinical application of glabridin is limited due to its poor water solubility and therefore low bioavailability, but studies have shown that this situation can be improved by combining it with $\beta$-Lactoglobulin. (Wei et al., 2018). These results indicate the potential of glabridin in OA prevention and treatment as a potential drug for OA.

\subsubsection{Rhoifolin}

Rhoifolin (ROF) is a flavanone derived from Rhus succedanea L. that exhibits significant antioxidant and anti-inflammatory effects in a variety of diseases (Fang et al., 2020; Peng et al., 2020). In vitro, ROF attenuated osteoclast-stimulated osteolysis by inhibiting MAPK and NF- $\kappa \mathrm{B}$ signaling pathways (Liao et al., 2019). Yan et al. showed that ROF significantly blocked phosphorylation of $\mathrm{P} 38 / \mathrm{JNK}$ and $\mathrm{PI} 3 \mathrm{~K} / \mathrm{AKT} / \mathrm{mTOR}$ pathways to enhance autophagy and protected rat chondrocytes from IL$1 \beta$-induced inflammation and apoptosis. In vivo, intra-articular injection of ROF also significantly improved cartilage damage in a rat $\mathrm{OA}$ model, affirming the potential role of $\mathrm{ROF}$ in $\mathrm{OA}$ treatment by regulating autophagy (Yan et al., 2021). However, the optimal dose of ROF for in vivo application is unclear and needs to be further investigated.

\subsubsection{Eupatilin}

Eupatilin is a flavonoid derived from Artemisia absinthium L. that exerts anti-apoptotic and anti-inflammatory effects in a variety of diseases (Choi et al., 2008; Cai et al., 2012). Recent studies suggest that eupatilin may be useful in arthritis (Jeong et al., 2015; Kim et al., 2015). Lou et al. found that eupatilin attenuated IL $-1 \beta$ induced apoptosis in rat chondrocytes by modulating autophagyrelated protein levels, that is, by increasing senstrin 2 and decreasing mTOR, which activated autophagy in a dosedependent manner (Lou et al., 2019). Eupatilin at 33-85 mM exerts moderate toxic effects on human and mice cancer cells, but more eupatilin toxicity studies on chondrocytes are needed (Zater et al., 2016).

\subsubsection{Sinensetin}

Sinensetin is a polymethoxylated flavonoid derived from Citrus L. with potent anti-inflammatory activity (Han Jie et al., 2020). Sinensetin has been shown to mediate the AMPK/mTOR signaling pathway to promote autophagy and thereby treat liver cancer (Kim et al., 2020). In vitro experiments by Zhou et al. showed that Sinensetin activated the AMPK/mTOR signaling pathway in a time- and dose-dependent mannersignificantly improved the autophagy function of mice chondrocytes and inhibited TBHP-induced apoptosis in mouse chondrocytes. In vivo experiments yielded similar results, and Sinensetin protected against DMM-induced mice (Zhou et al., 2021b). These results provide evidence that Sinensetin could be a potential candidate for the treatment of OA.

\subsection{Terpenoids}

Terpenoids are the largest class of natural products, most of which are of plant origin, and their biological properties, mainly anti-proliferative and apoptotic, have been shown to play an important role in cancer prevention and health promotion through the promotion of autophagy (Martel et al., 2019; ElBaba et al., 2021). Therefore, plant-derived terpenoids components will provide a novel approach for mediating autophagy in the treatment of OA.

\subsubsection{Morroniside}

Corni Fructus (CF) is one of the most important botanical products in traditional Chinese medicine and its compound has been used clinically for a long time in the treatment of OA (Chen et al., 2014a). In latest years, some compounds extracted from CF such as cyclic enol ether glycosides and active ingredients have been found to have antioxidant and anti-inflammatory effects. Morroniside, an water-soluble iridoid glycoside derived from $\mathrm{CF}$, has a variety of bioactive substances with antioxidant and anti-inflammatory effects (Park et al., 2009; Wang et al., 2010; Chen et al., 2014b). It has been shown in many in vivo and in vitro experiments that morroniside improves chondrocyte function by modulating autophagy to slow $\mathrm{OA}$ progression. Xiao et al. conducted in vitro experiments with human chondrocytes and showed that morroniside decreased the level of LC3 conversion in chondrocytes, thus promoting chondrocyte proliferation, survival and matrix synthesis. Interestingly, morroniside also inhibited the autophagic response of chondrocytes by promoting $\mathrm{PI} 3 \mathrm{~K} / \mathrm{AKT} / \mathrm{mTOR}$ signaling, while increasing the activity of AKT and mTOR. However, overexpression of autophagy genes in the experiment enhanced the positive regulation of cell proliferation, survival and matrix synthesis by morroniside, suggesting that activation of autophagy facilitates the protective effect of morroniside on chondrocytes (Xiao et al., 2020). Furthermore, Yu et al. established a mouse model of OA by DMM surgery and used primary mouse chondrocytes induced by morroniside treatment with IL-1 $\beta$ as in vitro subjects. Morroniside was found to slow down the progression of $\mathrm{OA}$ 
by inhibiting the NF- $\kappa \mathrm{B}$ signaling pathway and suppressing the expression of MMP-13, Caspase-1 and NOD-like receptor family pyrin domain containing 3 (NLRP3) (Yu et al., 2021). Similarly, Cheng et al. treated human osteoarthritic chondrocytes with morroniside for in vitro experiments and found that morroniside could promote cell survival and matrix synthesis, and also induced an experimental OA model in rats by anterior cruciate ligament severance combined with medial meniscectomy (Hayami et al., 2003; Zhao et al., 2014), and found that intraarticular injection of morroniside reduced cartilage damage in an experimental model of OA rats (Cheng et al., 2015). Therefore, some drugs with autophagy-activating effects may serve as effective supplements to morroniside in the treatment of OA.

\subsubsection{Lycopene}

Lycopene (LYC), a lipid-soluble carotenoid naturally found in Solanum lycopersicum L, is a potent antioxidant with potential chondroprotective effects (Sachdeva and Chopra, 2015; Wang et al., 2016). It is shown in vitro experiments by Wu et al. that LYC may enhance autophagy and inhibit $\mathrm{H}_{2} \mathrm{O}_{2}$-induced inflammation and apoptosis in rat chondrocytes by suppressing mTOR levels in part through inhibition of MAPK and PI3K/AKT/NF- $\kappa B$ axis (Wu et al., 2021), thus LYC has potential therapeutic implications for mediating autophagy in the treatment of OA.

\subsubsection{Celastrol}

Celastrol is a natural triterpenoid found in traditional Chinese medicine botanical drugs Tripterygium wilfordii (Yang et al., 2006). Owing to its powerful anti-inflammatoryand antioxidant properties, celastrol has been used to treat a variety of diseases (Kannaiyan et al., 2011). Feng et al. found that celastrol restored IL- $1 \beta$-induced inhibition of autophagy in rat chondrocytes by inhibiting the NF- $\mathrm{B}$ signaling pathway, increased the expression levels of LC3-II and Beclin-1, and ameliorated IL-1 $\beta$-induced apoptosis in rat chondrocytes. In addition, celastrol decreased IL- $1 \beta$-stimulated phosphorylation of IкBa and P65. The therapeutic effect of celastrol on OA articular cartilage was also confirmed in the ACLT rat OA model (Feng et al., 2020). Celastrol is poorly water soluble, but it has been studied to effectively improve its bioavailability through galactosylated liposomes (Chen et al., 2020a). These results suggest that celastrol has potential in the prevention and treatment of OA.

\subsection{Coumarins}

Coumarins are different species of plant-derived secondary metabolites that have anti-inflammatory and anti-apoptotic properties and have recently been found to treat cancer by mediating autophagy (Guo et al., 2019; Rodríguez-Hernández et al., 2020). Accordingly, it is possible that these plant-derived coumarins mediate the autophagic pathway for the treatment of OA.

\subsubsection{Isoimperatorin}

Isoimperatorin is an linear furanocoumarin isolated from the Angelica dahurica (Wei and Ito, 2006). It has been demonstrated that isoimperatorin may exert anti-osteoarthritic effects by inhibiting COX-2 production in a mouse model (Moon et al., 2008). Ouyang et al. found that isoimperatorin activated autophagy by downregulating the mTORC1 signaling pathway in a dose-dependent manner in mouse chondrocytes, and downregulated the expression of MMP13, Runt-related transcription factor 2 (Runx2), and Vascular endothelial growth factor (VEGF) expression of inflammatory factors, thereby ameliorating articular cartilage degeneration in a mouse DMM model (Ouyang et al., 2017). Thus, isoimperatorin activates autophagy in a dose-dependent manner to down-regulate the level of inflammatory factors in cartilage and thus anti-osteoarthritis. Isoimperatorin was found to have toxic effects on human tumor cell lines, but more data is needed on its effects on chondrocytes (Kim et al., 2007).

\subsubsection{Isopsoralen}

Isopsoralen is a linear furanocoumarin isolated from the fruit of Cullen corylifolium (L.) Medik. and has various pharmacological effects such as anti-inflammatory, anti-oxidative stress (Li et al., 2019c; Zhang et al., 2019). Isopsoralen has been found to promote chondrocyte differentiation (Li et al., 2012). A study by Chen et al. showed that isopsoralen significantly enhanced autophagic flux by reducing the expression of LC3-II and sqstm1/p62, which resulted in a protective effect against il-1 $\beta$-induced apoptosis in rat chondrocytes (Chen et al., 2020b). isopsoralen deserves consideration as a therapeutic agent for OA.

\subsection{Saponin}

Saponins originating from different plants have also been found to exert anti-inflammatory and antioxidant activity through the mediation of autophagy and thus be used in the treatment of various diseases (Zhou et al., 2019; Luo et al., 2020). Saponins have potential in mediating autophagic pathways in the treatment of OA.

\subsubsection{Astragaloside IV}

Astragaloside IV (AST) is a unique active saponin compound extracted from Astragalus mongholicus Bunge, which has been found to protect against IL- $1 \beta$-induced joint inflammation and cartilage damage (Wang and Chen, 2014). Liu et al. treated chondrocytes from OA patients induced by IL- $1 \beta$ with AST and demonstrated that AST increased chondrocyte autophagic flux, reversed the expression of LC-3II/I and p62, significantly inhibited IL-1 $\beta$-induced apoptosis, and maintained cell viability (Liu et al., 2017). AST may be a new candidate for the treatment of OA because of its potential to mediate autophagy to regulate cartilage function. However, the gastrointestinal absorption of AST is very low, with a bioavailability of $2.2 \%$ in rats, thus limiting its clinical application ( $\mathrm{Gu}$ et al., 2004). More research is needed to make it better applied in the clinical treatment of OA.

\subsubsection{Huzhangoside D}

Huzhangoside D is a saponin isolated from Clematis graveolens Lindl, the latter being used to treat inflammation (Kawata et al., 1998). Zhang et al. treated an ACLT-induced KOA rat model with huzhangoside $\mathrm{D}$ and found that huzhangoside $\mathrm{D}$ may activate autophagy through downregulation of AKT and mTOR signaling 
pathway activity to activate autophagy, thereby upregulating the levels of autophagy-associated proteins beclin-1, ATG5, ATG7 and LC3. Meanwhile the levels of pro-inflammatory cytokines including TNF- $\alpha$, IL- 6 and IL- $1 \beta$ were decreased and the levels of anti-inflammatory cytokines such as IL-10 were increased, and the damage to cartilage structures and the function of cartilage in KOA rat models were restored to some extent (Zhang et al., 2021).

\subsection{Small-Molecule Chemicals}

In addition to the above phytochemicals, a number of smallmolecule chemicals derived from plants, such as various natural compounds and compound analogues, have also been found to enhance autophagy to treat various diseases (Jang et al., 2019; Wu et al., 2020). These plant-derived small molecules would be able to mediate autophagy to treat OA, but more research is needed.

\subsection{1 $\beta$-ecdysterone}

$\beta$-ecdysterone (Ecd) is an estrogen analog isolated from Achyranthes bidentata with various physiological effects such as anti-fatigue, pro-proliferative and hypolipidemic (Xu et al., 2018). It was found that Ecd inhibited IL- $1 \beta$-induced apoptosis and inflammation in rat chondrocytes by inhibiting the NF- $\kappa \mathrm{B}$ signaling pathway (Zhang et al., 2014). Tang used Ecd to intervene in a rat OA model established by monoiodoacetic acid (MIA), and the results showed that Ecd may induce chondrogenesis through the down-regulation of PI3K/AKT/ mTOR signaling pathway induced chondrocyte autophagy and downregulated the expression of PI3K, mTOR, and caspase-3, thereby reducing OA-like symptoms (Tang et al., 2020). Evidence related to Ecd improving chondrocyte homeostasis through mediated autophagy requires further examination.

\subsubsection{Dihydroartemisinin}

Dihydroartemisinin (DHA), a semisynthetic derivative of Artemisinin (ART), has fewer side effects than ART, the main phytochemical extracted from Artemisia annua L. (Tu, 1999). It has been shown that DHA can inhibit estrogen deficiencyinduced osteoporosis and osteoblast remodeling (Zhou et al., 2016). Jiang et al. have found in vitro experiments that DHA inhibits TNF- $\alpha$-induced NF- $\kappa B$ pathway activation and promote autophagy in rat chondrocytes thereby inhibiting chondrocyte catabolism and inflammatory factor levels, thus DHA has potential in improving OA through enhanced autophagy (Jiang et al., 2016). Currently, it has been found that the compounding of hydroxypropyl-beta-cyclodextrin (HP $\beta C D$ ) with DHA increases the solubility and stability of DHA, which makes it possible to apply DHA to clinical trials (Ansari et al., 2009).

\subsubsection{Shikimic Acid}

Shikimic acid (SA) is a hydroaromatic compound extracted from Artemisia absinthium L, which has been shown to have significant anti-inflammatory effects (Kolodziej et al., 2008). Another study showed that SA can inhibit osteoclastogenesis by inhibiting NF$\kappa \mathrm{B}$ and MAPK pathways, suggesting its potential role in the treatment of OA (Chen et al., 2018). In vitro and in vivo experiments have recently demonstrated that SA can delay OA progression by enhancing autophagy-mediated cartilage homeostasis. You et al. found that SA inhibited IL- $1 \beta$-induced mitogen activation by inhibiting phosphorylation of ERK, p38, JNK, p65, and MAPK and NF-kB pathway activation and attenuated the expression of inflammatory and apoptotic factors, such as iNOS, COX2, MMPs and ADAMTS5, thereby alleviating IL-1 $\beta$-induced inflammatory responses, dysregulation of cartilage anabolism and catabolism, and autophagic damage in human chondrocytes. In addition, in vivo experiments revealed that SA reduced cartilage erosion and proteoglycan loss in ACLT rats, thus providing new evidence for water-soluble SA to treat and prevent the development of OA (Steimer et al., 2015; You et al., 2021).

\subsubsection{Sinomenium}

Sinomenium (SIN) is a natural alkaloid extracted from the medicinal plant Sinomenium acutum (Thunb.) Rehder and E.H.Wilson, which decreases the protein level of MMP-13, a marker of cartilage degradation in rats, thereby resisting cartilage degradation, and blocks collagen-induced arthritis through NF$\mathrm{\kappa B}$ signaling and downregulates the expression of MMP13 (Ju et al., 2010; Sun et al., 2014). Chen et al. found that SIN improved IL- $1 \beta$-induced degradation of the extracellular matrix in mouse chondrocytes at least in part through activation of autophagy. Similarly, by intra-articular injection of CM-SIN and GelMA in ACLT surgery-induced mice, SIN was also found to improve cartilage matrix degradation, at least in part, by inducing autophagy in vivo (Chen et al., 2016).

\subsubsection{Tetrahydrohyperforin}

Tetrahydrohyperforin (IDN5706) is a tetrahydro derivative of hyperforin, one of the main active components of Hypericum perforatum L. extracts, which has many properties, including anti-inflammatory and anti-tumor properties (Koeberle et al., 2011). In vitro studies by Zhang et al. demonstrated that IDN5706 decreased the levels of MMP-13 and IL- 6 in OA rat chondrocytes. At the same time, the levels of LC3-II, Beclin-1 and Atg5 were increased and the levels of $p$-mTOR were decreased. IDN5706 was also found to attenuate the degeneration of OA rat model induced by intra-articular injection of collagenase solution articular cartilage through activation of autophagy (Zhang et al., 2018bbib_Zhang_et_al_2018a).

\section{SUMMARY AND PROSPECT}

In the development of $\mathrm{OA}$, the activation of autophagy has positive significance for the survival of chondrocytes, and autophagy as a therapeutic target for OA has a broad clinical application prospect. Targeted application of drugs to regulate chondrocyte autophagy levels is expected to provide more options for the clinical treatment of OA. In recent years, plant extracts and phytochemicals isolated from the former have gradually gained popularity and attracted widespread attention. They have definite anti-osteoarthritic ability, which is mainly achieved by mediating relevant autophagy-related 
pathways, and improving chondrocyte autophagy. Given the cost-effectiveness and wide availability of phytochemicals, and the growing awareness of their role in promoting chondrocyte autophagy and thus treating $\mathrm{OA}$, research on improving $\mathrm{OA}$ is rapidly increasing. Phytochemicals emerge as an important source for the development of novel OA therapeutics, providing a valuable source of $\mathrm{OA}$ therapeutics, lead compounds or adjuvants for the discovery of new drugs that exert multifaceted biological activities in maintaining human health and preventing disease. However, except from curcumin and RSV (Chin, 2016; Nguyen et al., 2017), most of the current experimental designs are confined to preclinical studies such as cellular and animal experiments, and it remains unclear whether they can be applied in the clinics. Furthermore, there are still many issues to be solved in this field. First, in vitro experiments have demonstrated curcumin at concentrations of $25 \mu \mathrm{M}$ and above is cytotoxic to primary chondrocytes after 5 days in culture, but most phytochemicals still lack validated clinical trials to demonstrate their toxicity (Clutterbuck et al., 2013). Second, some studies have demonstrated a dose-effect effect of curcumin, EGCG and HT in the improvement of chondrocyte function, so it is possible that different doses of phytochemicals have different efficacy in the treatment of OA, and there are still no comparative studies on the effectiveness of other phytochemicals with different doses (Chowdhury et al., 2008; Oliviero et al., 2013; Zhi et al., 2018). Third, it has been argued that phytochemicals such as curcumin, resveratrol, and EGCG may be pan-assay interference compounds (PAINS), that is, by interfering with various reactions in the assays, such as chemical aggregation, the presence of a reactive michael acceptor, and fluorescence activity, thus making the assays readout appear false positive rather than through specific compound/target interactions. Moreover, its experimental results are strongly influenced by the experimental conditions, such as the purity of the phytochemical extracts (Baell, 2016). The pharmacological effects of these phytochemicals in a variety of diseases have attracted widespread attention from researchers as a panaceas, but this invalid metabolic panaceas (IMPS) may lead to a waste of research resources in drug development, so further exploration in the control of experimental conditions and development is needed to minimize the effect of false positives (Bisson et al., 2016). Autophagy can be used as a protective mechanism to degrade and remove damaged organelles and proteins, and thus can be used to treat various aging-related diseases (Ren and Zhang, 2018). In oxidative stress environments, autophagy is activated to eliminating intracellular ROS to protect cells from apoptosis, as well as to prevent tissue inflammation by downregulating inflammation-related signals, reducing inflammatory cytokine expression, and promoting apoptotic corpse clearance (Levine et al., 2011; Yun et al., 2020). Current studies have shown that activation of autophagy can protect chondrocytes from oxidative stress and inflammation by down-regulating the levels of inflammation and oxidative stress-related proteins such as iNOS and MMPs and upregulating autophagy-related factors such as mTOR and AMPK to maintain the structural integrity of the cartilage matrix against early OA (Duan et al., 2020), but the role of autophagy in different periods of OA is different, and further studies are needed on the mechanism of autophagy activation on advanced $\mathrm{OA}$ and its effects. Besides, it has been shown by another study that curcumin has potential therapeutic potential for diseases such as viral infections by modulating APE1 and thus affecting the common redox response in the body, and therefore is not a PAINS (Li et al., 2019a). Since Apurinic/apyrimidinic endonuclease 1 (APE1) can promote autophagy, it is possible that phytochemicals like curcumin could enhance the regulation of APE1 by targeting autophagy to treat OA, thus avoiding becoming an IMPS and the failure of drug development due to false positives in its pharmacological effects, but the role of phytochemicals in mediating autophagy in different periods of $\mathrm{OA}$ and the specific molecular mechanisms of their anti-osteoarthritis function need to be further investigated, and further experimental demonstration on the existing basis is needed (Li et al., 2019d; Tang et al., 2019). Obviously, our review has the limitation that there is a risk of obtaining false-positive results. However, in the context of developing natural products with the potential to target the treatment of OA, our review remains a summary and critical evaluation based on the available evidence and provides a basis for further research and development. Therefore, the combined efforts of more relevant researchers and experts are needed to conduct systematic experimental design and experimental analysis and to establish an effective evaluation system so that phytochemicals can more effectively benefit patients with OA. It is hoped that increasingly extensive and well-designed pharmacological and clinical studies will enable safer and more rational use of these ancient botanical drugs based on conclusive evidence.

\section{AUTHOR CONTRIBUTIONS}

MS and XZ conceptualized the review. ZT drafted the manuscript, drew illustrations of autophagy-related pathways and processed them at the same time. MS and XZ revised and supplemented the manuscript. All the authors participated in writing and giving feedback on the manuscript. All authors have read and approved the final manuscript.

\section{FUNDING}

This work was supported by the Scientific research funding project of the Department of Education of Liaoning Province (LJC2019ST02), 2019 Outstanding Talents Support Plan for Higher Education Institutions in Liaoning Province (WR2019024) and the Scientific research funding project of the Department of Education of Liaoning Province (LJKZ1048). 


\section{REFERENCES}

Ansari, M. T., Iqbal, I., and Sunderland, V. B. (2009). Dihydroartemisinincyclodextrin Complexation: Solubility and Stability. Arch. Pharm. Res. 32 (1), 155-165. doi:10.1007/s12272-009-1130-4

Ansari, M. Y., Ahmad, N., and Haqqi, T. M. (2018a). Butein Activates Autophagy through AMPK/TSC2/ULK1/mTOR Pathway to Inhibit IL-6 Expression in IL$1 \beta$ Stimulated Human Chondrocytes. Cell Physiol Biochem 49 (3), 932-946. doi:10.1159/000493225

Ansari, M. Y., Ahmad, N., and Haqqi, T. M. (2020). Oxidative Stress and Inflammation in Osteoarthritis Pathogenesis: Role of Polyphenols. Biomed. Pharmacother. 129, 110452. doi:10.1016/j.biopha.2020.110452

Ansari, M. Y., Khan, N. M., Ahmad, I., and Haqqi, T. M. (2018b). Parkin Clearance of Dysfunctional Mitochondria Regulates ROS Levels and Increases Survival of Human Chondrocytes. Osteoarthritis Cartilage 26 (8), 1087-1097. doi:10.1016/ j.joca.2017.07.020

Ansari, M. Y., Khan, N. M., and Haqqi, T. M. (2017). A Standardized Extract of Butea Monosperma (Lam.) Flowers Suppresses the IL-1 $\beta$-induced Expression of IL-6 and Matrix-Metalloproteases by Activating Autophagy in Human Osteoarthritis Chondrocytes. Biomed. Pharmacother. 96, 198-207. doi:10.1016/j.biopha.2017.09.140

Aparicio-Soto, M., Sánchez-Fidalgo, S., González-Benjumea, A., Maya, I., Fernández-Bolaños, J. G., and Alarcón-de-la-Lastra, C. (2015). Naturally Occurring Hydroxytyrosol Derivatives: Hydroxytyrosyl Acetate and 3,4dihydroxyphenylglycol Modulate Inflammatory Response in Murine Peritoneal Macrophages. Potential Utility as New Dietary Supplements. J. Agric. Food Chem. 63 (3), 836-846. doi:10.1021/jf503357s

Baell, J. B. (2016). Feeling Nature's PAINS: Natural Products, Natural Product Drugs, and Pan Assay Interference Compounds (PAINS). J. Nat. Prod. 79 (3), 616-628. doi:10.1021/acs.jnatprod.5b00947

Bai, Y., Liu, C., Fu, L., Gong, X., Dou, C., Cao, Z., et al. (2018). Mangiferin Enhances Endochondral Ossification-Based Bone Repair in Massive Bone Defect by Inducing Autophagy through Activating AMP-Activated Protein Kinase Signaling Pathway. FASEB J. 32 (8), 4573-4584. doi:10.1096/fj.201701411R

Barranco, C. (2015). Osteoarthritis: Activate Autophagy to Prevent Cartilage Degeneration? Nat. Rev. Rheumatol. 11 (3), 127. doi:10.1038/nrrheum.2015.12

Basu, A., Schell, J., and Scofield, R. H. (2018). Dietary Fruits and Arthritis. Food Funct. 9 (1), 70-77. doi:10.1039/c7fo01435j

Benderdour, M., Martel-Pelletier, J., Pelletier, J. P., Kapoor, M., Zunzunegui, M. V., and Fahmi, H. (2015). Cellular Aging, Senescence and Autophagy Processes in Osteoarthritis. Curr. Aging Sci. 8 (2), 147-157. doi:10.2174/ 1874609808666150727111530

Bert, J. M., and Bert, T. M. (2014). Nonoperative Treatment of Unicompartmental Arthritis: from Bracing to Injection. Clin. Sports Med. 33 (1), 1-10. doi:10.1016/ j.csm.2013.08.002

Bisson, J., McAlpine, J. B., Friesen, J. B., Chen, S. N., Graham, J., and Pauli, G. F. (2016). Can Invalid Bioactives Undermine Natural Product-Based Drug Discovery? J. Med. Chem. 59 (5), 1671-1690. doi:10.1021/ acs.jmedchem.5b01009

Bohlooli, S., Jastan, M., Nakhostin-Roohi, B., Mohammadi, S., and Baghaei, Z. (2012). A Pilot Double-Blinded, Randomized, Clinical Trial of Topical virgin Olive Oil versus Piroxicam Gel in Osteoarthritis of the Knee. J. Clin. Rheumatol. 18 (2), 99-101. doi:10.1097/RHU.0b013e31824a47b5

Bolduc, J. A., Collins, J. A., and Loeser, R. F. (2019). Reactive Oxygen Species, Aging and Articular Cartilage Homeostasis. Free Radic. Biol. Med. 132, 73-82. doi:10.1016/j.freeradbiomed.2018.08.038

Cai, M., Phan, P. T., Hong, J. G., Kim, D. H., Kim, J. M., Park, S. J., et al. (2012). The Neuroprotective Effect of Eupatilin against Ischemia/reperfusion-Induced Delayed Neuronal Damage in Mice. Eur. J. Pharmacol. 689 (1-3), 104-110. doi:10.1016/j.ejphar.2012.05.042

Cameron, M., and Chrubasik, S. (2014). Oral Herbal Therapies for Treating Osteoarthritis. Cochrane Database Syst. Rev. 5, CD002947. doi:10.1002/ 14651858.CD002947.pub2

Caramés, B., Olmer, M., Kiosses, W. B., and Lotz, M. K. (2015). The Relationship of Autophagy Defects to Cartilage Damage during Joint Aging in a Mouse Model. Arthritis Rheumatol. 67 (6), 1568-1576. doi:10.1002/art.39073
Caramés, B., Taniguchi, N., Otsuki, S., Blanco, F. J., and Lotz, M. (2010). Autophagy Is a Protective Mechanism in normal Cartilage, and its AgingRelated Loss Is Linked with Cell Death and Osteoarthritis. Arthritis Rheum. 62 (3), 791-801. doi:10.1002/art.27305

Cerdá, B., Tomás-Barberán, F. A., and Espín, J. C. (2005). Metabolism of Antioxidant and Chemopreventive Ellagitannins from Strawberries, Raspberries, Walnuts, and Oak-Aged Wine in Humans: Identification of Biomarkers and Individual Variability. J. Agric. Food Chem. 53 (2), 227-235.

Cetrullo, S., D'Adamo, S., Guidotti, S., Borzì, R. M., and Flamigni, F. (2016). Hydroxytyrosol Prevents Chondrocyte Death under Oxidative Stress by Inducing Autophagy through Sirtuin 1-dependent and -independent Mechanisms. Biochim. Biophys. Acta 1860 (6), 1181-1191. doi:10.1016/ j.bbagen.2016.03.002

Charlier, E., Deroyer, C., Ciregia, F., Malaise, O., Neuville, S., Plener, Z., et al. (2019). Chondrocyte Dedifferentiation and Osteoarthritis (OA). Biochem. Pharmacol. 165, 49-65. doi:10.1016/j.bcp.2019.02.036

Chen, F. P., Chang, C. M., Hwang, S. J., Chen, Y. C., and Chen, F. J. (2014a). Chinese Herbal Prescriptions for Osteoarthritis in Taiwan: Analysis of National Health Insurance Dataset. BMC Complement Altern. Med. 14, 91. doi:10.1186/ 1472-6882-14-91

Chen, F. P., Li, B. S., and Tang, C. H. (2015). Nanocomplexation between Curcumin and Soy Protein Isolate: Influence on Curcumin Stability/ bioaccessibility and In Vitro Protein Digestibility. J. Agric. Food Chem. 63 (13), 3559-3569. doi:10.1021/acs.jafc.5b00448

Chen, J. P., Xu, D. G., Yu, X. Y., Zhao, F. M., Xu, D. Q., Zhang, X., et al. (2014b). Discrepancy between the Effects of Morronside on Apoptosis in Human Embryonic Lung Fibroblast Cells and Lung Cancer A549 Cells. Oncol. Lett. 7 (4), 927-932. doi:10.3892/ol.2014.1850

Chen, P., Xia, C., Mei, S., Wang, J., Shan, Z., Lin, X., et al. (2016). Intra-articular Delivery of Sinomenium Encapsulated by Chitosan Microspheres and PhotoCrosslinked GelMA Hydrogel Ameliorates Osteoarthritis by Effectively Regulating Autophagy. Biomaterials 81, 1-13. doi:10.1016/ j.biomaterials.2015.12.006

Chen, T., Zhou, R., Chen, Y., Fu, W., Wei, X., Ma, G., et al. (2021). Curcumin Ameliorates IL-1 $\beta$-induced Apoptosis by Activating Autophagy and Inhibiting the NF-Kb Signaling Pathway in Rat Primary Articular Chondrocytes. Cell Biol Int 45 (5), 976-988. doi:10.1002/cbin.11541

Chen, W. P., Tang, J. L., Bao, J. P., Hu, P. F., Shi, Z. L., and Wu, L. D. (2011). Antiarthritic Effects of Chlorogenic Acid in Interleukin-1 $\beta$-Induced Rabbit Chondrocytes and a Rabbit Osteoarthritis Model. Int. Immunopharmacol 11 (1), 23-28. doi:10.1016/j.intimp.2010.09.021

Chen, X., Hu, X., Hu, J., Qiu, Z., Yuan, M., and Zheng, G. (2020a). Celastrol-Loaded Galactosylated Liposomes Effectively Inhibit AKT/c-Met-Triggered Rapid Hepatocarcinogenesis in Mice. Mol. Pharm. 17 (3), 738-747. doi:10.1021/ acs.molpharmaceut.9b00428

Chen, X., Li, X., Zhai, X., Zhi, X., Cao, L., Qin, L., et al. (2018). Shikimic Acid Inhibits Osteoclastogenesis In Vivo and In Vitro by Blocking RANK/TRAF6 Association and Suppressing NF-Kb and MAPK Signaling Pathways. Cell Physiol Biochem 51 (6), 2858-2871. doi:10.1159/000496039

Chen, Z., Li, C., Qian, Y. H., Fu, Y., and Feng, Z. M. (2020b). Enhancement of Autophagy Flux by Isopsoralen Ameliorates Interleukin-1 $\beta$-Stimulated Apoptosis in Rat Chondrocytes. J. Asian Nat. Prod. Res. 22 (2), 179-192. doi:10.1080/10286020.2018.1537265

Cheng, L., Zeng, G., Liu, Z., Zhang, B., Cui, X., Zhao, H., et al. (2015). Protein Kinase B and Extracellular Signal-Regulated Kinase Contribute to the Chondroprotective Effect of Morroniside on Osteoarthritis Chondrocytes. J. Cell Mol Med 19 (8), 1877-1886. doi:10.1111/jcmm.12559

Chin, K. Y., and Pang, K. L. (2017). Therapeutic Effects of Olive and its Derivatives on Osteoarthritis: From Bench to Bedside. Nutrients 9 (10). doi:10.3390/ nu9101060

Chin, K. Y. (2016). The Spice for Joint Inflammation: Anti-inflammatory Role of Curcumin in Treating Osteoarthritis. Drug Des. Devel Ther. 10, 3029-3042. doi:10.2147/DDDT.S117432

Choi, E. J., Oh, H. M., Na, B. R., Ramesh, T. P., Lee, H. J., Choi, C. S., et al. (2008). Eupatilin Protects Gastric Epithelial Cells from Oxidative Damage and DownRegulates Genes Responsible for the Cellular Oxidative Stress. Pharm. Res. 25 (6), 1355-1364. doi:10.1007/s11095-008-9531-5 
Choi, E. M. (2011). Glabridin Protects Osteoblastic MC3T3-E1 Cells against Antimycin A Induced Cytotoxicity. Chem. Biol. Interact 193 (1), 71-78. doi:10.1016/j.cbi.2011.05.007

Chow, H. H., Cai, Y., Hakim, I. A., Crowell, J. A., Shahi, F., Brooks, C. A., et al. (2003). Pharmacokinetics and Safety of green tea Polyphenols after MultipleDose Administration of Epigallocatechin Gallate and Polyphenon E in Healthy Individuals. Clin. Cancer Res. 9 (9), 3312-3319.

Chowdhury, T. T., Salter, D. M., Bader, D. L., and Lee, D. A. (2008). Signal Transduction Pathways Involving P38 MAPK, JNK, NFkappaB and AP-1 Influences the Response of Chondrocytes Cultured in Agarose Constructs to IL-1beta and Dynamic Compression. Inflamm. Res. 57 (7), 306-313. doi:10.1007/s00011-007-7126-y

Clutterbuck, A. L., Allaway, D., Harris, P., and Mobasheri, A. (2013). Curcumin Reduces Prostaglandin E2, Matrix Metalloproteinase-3 and Proteoglycan Release in the Secretome of Interleukin $1 \beta$-Treated Articular Cartilage. F1000Res 2, 147. doi:10.12688/f1000research.2-147.v210.12688/ f1000research.2-147.v1

Cornwell, D. G., and Ma, J. (2008). Nutritional Benefit of Olive Oil: The Biological Effects of Hydroxytyrosol and its Arylating Quinone Adducts. J. Agric. Food Chem. 56 (19), 8774-8786. doi:10.1021/jf8015877

Cutolo, M., Berenbaum, F., Hochberg, M., Punzi, L., and Reginster, J. Y. (2015). Commentary on Recent Therapeutic Guidelines for Osteoarthritis. Semin. Arthritis Rheum. 44 (6), 611-617. doi:10.1016/j.semarthrit.2014.12.003

Dai, B., Zhong, T., Chen, Z.-X., Chen, W., Zhang, N., Liu, X.-L., et al. (2021a10122). Myricetin Slows Liquid-Liquid Phase Separation of Tau and Activates ATG5dependent Autophagy to Suppress Tau Toxicity. J. Biol. Chem. 297, 101222. doi:10.1016/j.jbc.2021.101222

Dai, J., Zhang, Y., Chen, D., Chen, D., Li, X., Wang, J., et al. (2021b). Glabridin Inhibits Osteoarthritis Development by Protecting Chondrocytes against Oxidative Stress, Apoptosis and Promoting mTOR Mediated Autophagy. Life Sci. 268, 118992. doi:10.1016/j.lfs.2020.118992

Doria, A., Gatto, M., and Punzi, L. (2013). Autophagy in Human Health and Disease. N. Engl. J. Med. 368 (19), 1845. doi:10.1056/NEJMc1303158

Duan, R., Xie, H., and Liu, Z. Z. (2020). The Role of Autophagy in Osteoarthritis. Front Cell Dev Biol 8, 608388. doi:10.3389/fcell.2020.608388

El-Baba, C., Baassiri, A., Kiriako, G., Dia, B., Fadlallah, S., Moodad, S., et al. (2021). Terpenoids' Anti-cancer Effects: Focus on Autophagy. Apoptosis 26 (9-10), 491-511. doi:10.1007/s10495-021-01684-y

Fang, J., Cao, Z., Song, X., Zhang, X., Mai, B., Wen, T., et al. (2020). Rhoifolin Alleviates Inflammation of Acute Inflammation Animal Models and LPSInduced RAW264.7 Cells via IKK $\beta / \mathrm{NF}-\mathrm{Kb}$ Signaling Pathway. Inflammation 43 (6), 2191-2201. doi:10.1007/s10753-020-01286-x

Farah, A., Monteiro, M., Donangelo, C. M., and Lafay, S. (2008). Chlorogenic Acids from green Coffee Extract Are Highly Bioavailable in Humans. J. Nutr. 138 (12), 2309-2315. doi:10.3945/jn.108.095554

Feng, K., Chen, H., and Xu, C. (2020). Chondro-protective Effects of Celastrol on Osteoarthritis through Autophagy Activation and NF-Kb Signaling Pathway Inhibition. Inflamm. Res. 69 (4), 385-400. doi:10.1007/s00011-020-01327-z

Foroutanfar, A., Mehri, S., Kamyar, M., Tandisehpanah, Z., and Hosseinzadeh, H. (2020). Protective Effect of Punicalagin, the Main Polyphenol Compound of Pomegranate, against Acrylamide-Induced Neurotoxicity and Hepatotoxicity in Rats. Phytother Res. 34 (12), 3262-3272. doi:10.1002/ptr.6774

Francioso, A., Mastromarino, P., Masci, A., d'Erme, M., and Mosca, L. (2014). Chemistry, Stability and Bioavailability of Resveratrol. Med. Chem. 10 (3), 237-245. doi:10.2174/15734064113096660053

Fuhrman, B., Volkova, N., Rosenblat, M., and Aviram, M. (2000). Lycopene Synergistically Inhibits LDL Oxidation in Combination with Vitamin E, Glabridin, Rosmarinic Acid, Carnosic Acid, or Garlic. Antioxid. Redox Signal 2 (3), 491-506. doi:10.1089/15230860050192279

Goel, A., Kunnumakkara, A. B., and Aggarwal, B. B. (2008). Curcumin as "Curecumin": from Kitchen to Clinic. Biochem. Pharmacol. 75 (4), 787-809. doi:10.1016/j.bcp.2007.08.016

Goldring, M. B., and Otero, M. (2011). Inflammation in Osteoarthritis. Curr. Opin. Rheumatol. 23 (5), 471-478. doi:10.1097/BOR.0b013e328349c2b1

Granados-Principal, S., Quiles, J. L., Ramirez-Tortosa, C. L., Sanchez-Rovira, P., and Ramirez-Tortosa, M. C. (2010). Hydroxytyrosol: from Laboratory Investigations to Future Clinical Trials. Nutr. Rev. 68 (4), 191-206. doi:10.1111/j.1753-4887.2010.00278.x
Gu, Y., Wang, G., Pan, G., Fawcett, J. P., A, J., and Sun, J. (2004). Transport and Bioavailability Studies of Astragaloside IV, an Active Ingredient in Radix Astragali. Basic Clin. Pharmacol. Toxicol. 95 (6), 295-298. doi:10.1111/ j.1742-7843.2004.t01-1-pto950508.x

Guo, H., He, Y., Bu, C., and Peng, Z. (2019). Antitumor and Apoptotic Effects of 5methoxypsoralen in U87MG Human Glioma Cells and its Effect on Cell Cycle, Autophagy and PI3K/Akt Signaling Pathway. Arch. Med. Sci. 15 (6), 1530-1538. doi:10.5114/aoms.2019.81729

Han Jie, L., Jantan, I., Yusoff, S. D., Jalil, J., and Husain, K. (2020). Sinensetin: An Insight on its Pharmacological Activities, Mechanisms of Action and Toxicity. Front Pharmacol. 11, 553404. doi:10.3389/fphar.2020.553404

Hara, T., Nakamura, K., Matsui, M., Yamamoto, A., Nakahara, Y., SuzukiMigishima, R., et al. (2006). Suppression of Basal Autophagy in Neural Cells Causes Neurodegenerative Disease in Mice. Nature 441 (7095), 885-889. doi: $10.1038 /$ nature 04724

Haseeb, A., Chen, D., and Haqqi, T. M. (2013). Delphinidin Inhibits IL-1 $\beta$-induced Activation of NF-Kb by Modulating the Phosphorylation of IRAK-1(Ser376) in Human Articular Chondrocytes. Rheumatology (Oxford) 52 (6), 998-1008. doi:10.1093/rheumatology/kes363

Hayami, T., Funaki, H., Yaoeda, K., Mitui, K., Yamagiwa, H., Tokunaga, K., et al. (2003). Expression of the Cartilage Derived Anti-angiogenic Factor Chondromodulin-I Decreases in the Early Stage of Experimental Osteoarthritis. J. Rheumatol. 30 (10), 2207-2217.

Hoelzl, C., Knasmüller, S., Wagner, K. H., Elbling, L., Huber, W., Kager, N., et al. (2010). Instant Coffee with High Chlorogenic Acid Levels Protects Humans against Oxidative Damage of Macromolecules. Mol. Nutr. Food Res. 54 (12), 1722-1733. doi:10.1002/mnfr.201000048

Hong, P., Liu, Q. W., Xie, Y., Zhang, Q. H., Liao, L., He, Q. Y., et al. (2020). Echinatin Suppresses Esophageal Cancer Tumor Growth and Invasion Through Inducing AKT/mTOR-Dependent Autophagy and Apoptosis. Cell Death Dis. 11 (7), 524. doi:10.1038/s41419-020-2730-7

Hou, S., Wang, F., Li, Y., Li, Y., Wang, M., Sun, D., et al. (2012). Pharmacokinetic Study of Mangiferin in Human Plasma after Oral Administration. Food Chem. 132 (1), 289-294. doi:10.1016/j.foodchem.2011.10.079

Hu, J., Zhou, J., Wu, J., Chen, Q., Du, W., Fu, F., et al. (2020). Loganin Ameliorates Cartilage Degeneration and Osteoarthritis Development in an Osteoarthritis Mouse Model through Inhibition of NF-Kb Activity and Pyroptosis in Chondrocytes. J. Ethnopharmacol 247, 112261. doi:10.1016/ j.jep.2019.112261

Hu, T., He, X. W., Jiang, J. G., and Xu, X. L. (2014). Hydroxytyrosol and its Potential Therapeutic Effects. J. Agric. Food Chem. 62 (7), 1449-1455. doi:10.1021/jf405820v

Hua, W., Zhang, Y., Wu, X., Kang, L., Tu, J., Zhao, K., et al. (2018). Icariin Attenuates Interleukin-1 $\beta$-Induced Inflammatory Response in Human Nucleus Pulposus Cells. Curr. Pharm. Des. 23 (39), 6071-6078. doi:10.2174/ 1381612823666170615112158

Huang, H. T., Cheng, T. L., Ho, C. J., Huang, H. H., Lu, C. C., Chuang, S. C., et al. (2020). Intra-Articular Injection of (-)-Epigallocatechin 3-Gallate to Attenuate Articular Cartilage Degeneration by Enhancing Autophagy in a Post-Traumatic Osteoarthritis Rat Model. Antioxidants (Basel) 10 (1). doi:10.3390/ antiox 10010008

Hunter, D. J., and Bierma-Zeinstra, S. (2019). Osteoarthritis. Lancet 393 (10182), 1745-1759. doi:10.1016/S0140-6736(19)30417-9

Hussain, S. A., Marouf, B. H., Ali, Z. S., and Ahmmad, R. S. (2018). Efficacy and Safety of Co-administration of Resveratrol with Meloxicam in Patients with Knee Osteoarthritis: a Pilot Interventional Study. Clin. Interv. Aging 13, 1621-1630. doi:10.2147/cia.S172758

Isbrucker, R. A., Edwards, J. A., Wolz, E., Davidovich, A., and Bausch, J. (2006). Safety Studies on Epigallocatechin Gallate (EGCG) Preparations. Part 2: Dermal, Acute and Short-Term Toxicity Studies. Food Chem. Toxicol. 44 (5), 636-650. doi:10.1016/j.fct.2005.11.003

Jang, H. J., Yang, K. E., Hwang, I. H., Huh, Y. H., Kim, D. J., Yoo, H. S., et al. (2019). Cordycepin Inhibits Human Ovarian Cancer by Inducing Autophagy and Apoptosis through Dickkopf-Related Protein $1 / \beta$-Catenin Signaling. Am. J. Transl Res. 11 (11), 6890-6906.

Jeong, J. H., Moon, S. J., Jhun, J. Y., Yang, E. J., Cho, M. L., and Min, J. K. (2015). Eupatilin Exerts Antinociceptive and Chondroprotective Properties in a Rat Model of Osteoarthritis by Downregulating Oxidative Damage and Catabolic 
Activity in Chondrocytes. PLoS One 10 (6), e0130882. doi:10.1371/ journal.pone. 0130882

Jiang, J., Meng, Y., Hu, S., Botchway, B. O. A., Zhang, Y., and Liu, X. (2020). Saikosaponin D: A Potential Therapeutic Drug for Osteoarthritis. J. Tissue Eng. Regen. Med. 14 (8), 1175-1184. doi:10.1002/term.3090

Jiang, L. B., Meng, D. H., Lee, S. M., Liu, S. H., Xu, Q. T., Wang, Y., et al. (2016). Dihydroartemisinin Inhibits Catabolism in Rat Chondrocytes by Activating Autophagy via Inhibition of the NF-Kb Pathway. Sci. Rep. 6, 38979. doi:10.1038/srep38979

Jones, I. A., Togashi, R., Wilson, M. L., Heckmann, N., and Vangsness, C. T. (2019). Intra-articular Treatment Options for Knee Osteoarthritis. Nat. Rev. Rheumatol. 15 (2), 77-90. doi:10.1038/s41584-018-0123-4

Ju, X. D., Deng, M., Ao, Y. F., Yu, C. L., Wang, J. Q., Yu, J. K., et al. (2010). Protective Effect of Sinomenine on Cartilage Degradation and Chondrocytes Apoptosis. Yakugaku Zasshi 130 (8), 1053-1060. doi:10.1248/yakushi.130.1053

Kannaiyan, R., Shanmugam, M. K., and Sethi, G. (2011). Molecular Targets of Celastrol Derived from Thunder of God Vine: Potential Role in the Treatment of Inflammatory Disorders and Cancer. Cancer Lett. 303 (1), 9-20. doi:10.1016/ j.canlet.2010.10.025

Kawata, Y., Kizu, H., and Tomimori, T. (1998). Studies on the Constituents of Clematis Species. VII. Triterpenoid Saponins from the Roots of Clematis Terniflora DC. Var. Robusta Tamura. Chem. Pharm. Bull (Tokyo) 46 (12), 1891-1900. doi:10.1248/cpb.46.1891

Khan, N. M., Ahmad, I., and Haqqi, T. M. (2018). Nrf2/ARE Pathway Attenuates Oxidative and Apoptotic Response in Human Osteoarthritis Chondrocytes by Activating ERK1/2/ELK1-P70S6K-P90RSK Signaling axis. Free Radic. Biol. Med. 116, 159-171. doi:10.1016/j.freeradbiomed.2018.01.013

Kim, H. A., and Blanco, F. J. (2007). Cell Death and Apoptosis in Osteoarthritic Cartilage. Curr. Drug Targets 8 (2), 333-345. doi:10.2174/138945007779940025

Kim, J., Kim, Y., Yi, H., Jung, H., Rim, Y. A., Park, N., et al. (2015). Eupatilin Ameliorates Collagen Induced Arthritis. J. Korean Med. Sci. 30 (3), 233-239. doi:10.3346/jkms.2015.30.3.233

Kim, J. H., Jeon, J., Shin, M., Won, Y., Lee, M., Kwak, J. S., et al. (2014). Regulation of the Catabolic cascade in Osteoarthritis by the Zinc-ZIP8-MTF1 axis. Cell 156 (4), 730-743. doi:10.1016/j.cell.2014.01.007

Kim, S. M., Ha, S. E., Lee, H. J., Rampogu, S., Vetrivel, P., Kim, H. H., et al. (2020). Sinensetin Induces Autophagic Cell Death through P53-Related AMPK/mTOR Signaling in Hepatocellular Carcinoma HepG2 Cells. Nutrients 12 (8). doi:10.3390/nu12082462

Kim, Y. K., Kim, Y. S., and Ryu, S. Y. (2007). Antiproliferative Effect of Furanocoumarins from the Root of Angelica Dahurica on Cultured Human Tumor Cell Lines. Phytother Res. 21 (3), 288-290. doi:10.1002/ptr.2043

Kloppenburg, M., and Berenbaum, F. (2020). Osteoarthritis Year in Review 2019: Epidemiology and Therapy. Osteoarthritis Cartilage 28 (3), 242-248. doi:10.1016/j.joca.2020.01.002

Koeberle, A., Rossi, A., Bauer, J., Dehm, F., Verotta, L., Northoff, H., et al. (2011). Hyperforin, an Anti-inflammatory Constituent from St. John's Wort, Inhibits Microsomal Prostaglandin E(2) Synthase-1 and Suppresses Prostaglandin E(2) Formation In Vivo. Front Pharmacol. 2, 7. doi:10.3389/fphar.2011.00007

Kolodziej, H., Radtke, O. A., and Kiderlen, A. F. (2008). Stimulus (Polyphenol, IFN-Gamma, LPS)-dependent Nitric Oxide Production and Antileishmanial Effects in RAW 264.7 Macrophages. Phytochemistry 69 (18), 3103-3110. doi:10.1016/j.phytochem.2007.11.012

Kong, J., Wang, J., Gong, X., Zheng, X., and Chen, T. (2020). Punicalagin Inhibits Tert-Butyl Hydroperoxide-Induced Apoptosis and Extracellular Matrix Degradation in Chondrocytes by Activating Autophagy and Ameliorates Murine Osteoarthritis. Drug Des. Devel Ther. 14, 5521-5533. doi:10.2147/ DDDT.S282932

Kong, J. M., Chia, L. S., Goh, N. K., Chia, T. F., and Brouillard, R. (2003). Analysis and Biological Activities of Anthocyanins. Phytochemistry 64 (5), 923-933. doi:10.1016/s0031-9422(03)00438-2

Kraus, V. B., Blanco, F. J., Englund, M., Karsdal, M. A., and Lohmander, L. S. (2015). Call for Standardized Definitions of Osteoarthritis and Risk Stratification for Clinical Trials and Clinical Use. Osteoarthritis Cartilage 23 (8), 1233-1241. doi:10.1016/j.joca.2015.03.036

Lee, D. Y., Park, Y. J., Song, M. G., Kim, D. R., Zada, S., and Kim, D. H. (2020). Cytoprotective Effects of Delphinidin for Human Chondrocytes against
Oxidative Stress through Activation of Autophagy. Antioxidants (Basel) 9 (1). doi:10.3390/antiox 9010083

Lee, W., Ku, S. K., and Bae, J. S. (2015). Anti-inflammatory Effects of Baicalin, Baicalein, and Wogonin In Vitro and In Vivo. Inflammation 38 (1), 110-125. doi:10.1007/s10753-014-0013-0

Legeay, S., Trân, K., Abatuci, Y., Justiniano, H., Lugnier, C., Duval, O., et al. (2019). Design, Synthesis, Pharmacological Evaluation and Vascular Effects of Delphinidin Analogues. Curr. Pharm. Des. 24 (46), 5580-5589. doi:10.2174/ 1381612825666190206144913

Levine, B., and Kroemer, G. (2008). Autophagy in the Pathogenesis of Disease. Cell 132 (1), 27-42. doi:10.1016/j.cell.2007.12.018

Levine, B., Mizushima, N., and Virgin, H. W. (2011). Autophagy in Immunity and Inflammation. Nature 469 (7330), 323-335. doi:10.1038/nature09782

Li, C., Li, Q., Mei, Q., and Lu, T. (2015). Pharmacological Effects and Pharmacokinetic Properties of Icariin, the Major Bioactive Component in Herba Epimedii. Life Sci. 126, 57-68. doi:10.1016/j.lfs.2015.01.006

Li, H., Zhong, C., Wang, Q., Chen, W., and Yuan, Y. (2019a). Curcumin Is an APE1 Redox Inhibitor and Exhibits an Antiviral Activity against KSHV Replication and Pathogenesis. Antivir. Res 167, 98-103. doi:10.1016/j.antiviral.2019.04.011

Li, L., Eun, J. S., Nepal, M., Ryu, J. H., Cho, H. K., Choi, B. Y., et al. (2012). Isopsoralen Induces Differentiation of Prechondrogenic ATDC5 Cells via Activation of MAP Kinases and BMP-2 Signaling Pathways. Biomol. Ther. (Seoul) 20 (3), 299-305. doi:10.4062/biomolther.2012.20.3.299

Li, X., Feng, K., Li, J., Yu, D., Fan, Q., Tang, T., et al. (2017a). Curcumin Inhibits Apoptosis of Chondrocytes through Activation ERK1/2 Signaling Pathways Induced Autophagy. Nutrients 9 (4). doi:10.3390/nu9040414

Li, Y., Wu, Y., Jiang, K., Han, W., Zhang, J., Xie, L., et al. (2019b2019). Mangiferin Prevents TBHP-Induced Apoptosis and ECM Degradation in Mouse Osteoarthritic Chondrocytes via Restoring Autophagy and Ameliorates Murine Osteoarthritis. Oxid Med. Cell Longev 2019, 8783197. doi:10.1155/ 2019/8783197

Li, Y. P., Wu, B., Liang, J., and Li, F. (2019c). Isopsoralen Ameliorates H2O2Induced Damage in Osteoblasts via Activating the Wnt/ $\beta$-Catenin Pathway. Exp. Ther. Med. 18 (3), 1899-1906. doi:10.3892/etm.2019.7741

Li, Y. S., Xiao, W. F., and Luo, W. (2017b). Cellular Aging towards Osteoarthritis. Mech. Ageing Dev. 162, 80-84. doi:10.1016/j.mad.2016.12.012

Li, Z., Cheng, J., and Liu, J. (2020). Baicalin Protects Human OA Chondrocytes against IL-1 $\beta$-Induced Apoptosis and ECM Degradation by Activating Autophagy via MiR-766-3p/AIFM1 Axis. Drug Des. Devel Ther. 14, 2645-2655. doi:10.2147/dddt.S255823

Li, Z., Wang, Y., Wu, L., Dong, Y., Zhang, J., Chen, F., et al. (2019d). Apurinic Endonuclease 1 Promotes the Cisplatin Resistance of Lung Cancer Cells by Inducing Parkin-mediated M-itophagy. Oncol. Rep. 42 (6), 2245-2254. doi:10.3892/or.2019.7345

Liao, S., Song, F., Feng, W., Ding, X., Yao, J., Song, H., et al. (2019). Rhoifolin Ameliorates Titanium Particle-Stimulated Osteolysis and Attenuates Osteoclastogenesis via RANKL-Induced NF-Kb and MAPK Pathways. J. Cell Physiol 234 (10), 17600-17611. doi:10.1002/jcp.28384

Liu, F., Li, L., Lu, W., Ding, Z., Huang, W., Li, Y. T., et al. (2020). Scutellarin Ameliorates Cartilage Degeneration in Osteoarthritis by Inhibiting the Wnt/ $\beta$-Catenin and MAPK Signaling Pathways. Int. Immunopharmacol 78, 105954. doi:10.1016/j.intimp.2019.105954

Liu, F., Yang, H., Li, D., Wu, X., and Han, Q. (2021). Punicalagin Attenuates Osteoarthritis Progression via Regulating Foxo1/Prg4/HIF3a axis. Bone 152, 116070. doi:10.1016/j.bone.2021.116070

Liu, J., Meng, Q., Jing, H., and Zhou, S. (2017). Astragaloside IV Protects against Apoptosis in Human Degenerative Chondrocytes through Autophagy Activation. Mol. Med. Rep. 16 (3), 3269-3275. doi:10.3892/mmr.2017.6980

Loeser, R. F., Collins, J. A., and Diekman, B. O. (2016). Ageing and the Pathogenesis of Osteoarthritis. Nat. Rev. Rheumatol. 12 (7), 412-420. doi:10.1038/nrrheum.2016.65

Lou, Y., Wu, J., Liang, J., Yang, C., Wang, K., Wang, J., et al. (2019). Eupatilin Protects Chondrocytes from Apoptosis via Activating Sestrin2-dependent Autophagy. Int. Immunopharmacol 75, 105748. doi:10.1016/ j.intimp.2019.105748

Luk, H. Y., Appell, C., Chyu, M. C., Chen, C. H., Wang, C. Y., Yang, R. S., et al. (2020). Impacts of Green Tea on Joint and Skeletal Muscle Health: Prospects of 
Translational Nutrition. Antioxidants (Basel) 9 (11). doi:10.3390/ antiox9111050

Luo, P., Gao, F., Niu, D., Sun, X., Song, Q., Guo, C., et al. (2019). The Role of Autophagy in Chondrocyte Metabolism and Osteoarthritis: A Comprehensive Research Review. Biomed. Res. Int. 2019, 5171602. doi:10.1155/2019/5171602

Luo, Y., Lu, S., Gao, Y., Yang, K., Wu, D., Xu, X., et al. (2020). Araloside C Attenuates Atherosclerosis by Modulating Macrophage Polarization via Sirt1Mediated Autophagy. Aging (Albany NY) 12 (2), 1704-1724. doi:10.18632/ aging. 102708

Maiti, K., Mukherjee, K., Gantait, A., Saha, B. P., and Mukherjee, P. K. (2007). Curcumin-phospholipid Complex: Preparation, Therapeutic Evaluation and Pharmacokinetic Study in Rats. Int. J. Pharm. 330 (1-2), 155-163. doi:10.1016/ j.ijpharm.2006.09.025

Mao, Q. Q., Xu, X. Y., Shang, A., Gan, R. Y., Wu, D. T., Atanasov, A. G., et al. (2020). Phytochemicals for the Prevention and Treatment of Gastric Cancer: Effects and Mechanisms. Int. J. Mol. Sci. 21 (2). doi:10.3390/ijms21020570

Martel, J., Ojcius, D. M., Ko, Y. F., Ke, P. Y., Wu, C. Y., Peng, H. H., et al. (2019). Hormetic Effects of Phytochemicals on Health and Longevity. Trends Endocrinol. Metab. 30 (6), 335-346. doi:10.1016/j.tem.2019.04.001

Martel-Pelletier, J., Barr, A. J., Cicuttini, F. M., Conaghan, P. G., Cooper, C., Goldring, M. B., et al. (2016). Osteoarthritis. Nat. Rev. Dis. Primers 2, 16072. doi:10.1038/nrdp.2016.72

Mi, B., Wang, J., Liu, Y., Liu, J., Hu, L., Panayi, A. C., et al. (2018). Icariin Activates Autophagy via Down-Regulation of the NF-Kb Signaling-Mediated Apoptosis in Chondrocytes. Front Pharmacol. 9, 605. doi:10.3389/fphar.2018.00605

Mizushima, N., Levine, B., Cuervo, A. M., and Klionsky, D. J. (2008). Autophagy Fights Disease through Cellular Self-Digestion. Nature 451 (7182), 1069-1075. doi:10.1038/nature06639

Mizushima, N., and Yoshimori, T. (2007). How to Interpret LC3 Immunoblotting. Autophagy 3 (6), 542-545. doi:10.4161/auto.4600

Mobasheri, A., Rayman, M. P., Gualillo, O., Sellam, J., van der Kraan, P., and Fearon, U. (2017). The Role of Metabolism in the Pathogenesis of Osteoarthritis. Nat. Rev. Rheumatol. 13 (5), 302-311. doi:10.1038/nrrheum.2017.50

Moon, T. C., Jin, M., Son, J. K., and Chang, H. W. (2008). The Effects of Isoimperatorin Isolated from Angelicae Dahuricae on Cyclooxygenase-2 and 5-lipoxygenase in Mouse Bone Marrow-Derived Mast Cells. Arch. Pharm. Res. 31 (2), 210-215. doi:10.1007/s12272-001-1143-0

Musumeci, G., Trovato, F. M., Pichler, K., Weinberg, A. M., Loreto, C., and Castrogiovanni, P. (2013). Extra-virgin Olive Oil Diet and Mild Physical Activity Prevent Cartilage Degeneration in an Osteoarthritis Model: an In Vivo and In Vitro Study on Lubricin Expression. J. Nutr. Biochem. 24 (12), 2064-2075. doi:10.1016/j.jnutbio.2013.07.007

Nakamura, S., and Yoshimori, T. (2017). New Insights into AutophagosomeLysosome Fusion. J. Cell Sci 130 (7), 1209-1216. doi:10.1242/jcs.196352

Nelson, A. E. (2018). Osteoarthritis Year in Review 2017: Clinical. Osteoarthritis Cartilage 26 (3), 319-325. doi:10.1016/j.joca.2017.11.014

Netea-Maier, R. T., Plantinga, T. S., van de Veerdonk, F. L., Smit, J. W., and Netea, M. G. (2016). Modulation of Inflammation by Autophagy: Consequences for Human Disease. Autophagy 12 (2), 245-260. doi:10.1080/ 15548627.2015.1071759

Nguyen, C., Boutron, I., Baron, G., Coudeyre, E., Berenbaum, F., Poiraudeau, S., et al. (2017). Evolution of Pain at 3 Months by Oral Resveratrol in Knee Osteoarthritis (ARTHROL): Protocol for a Multicentre Randomised DoubleBlind Placebo-Controlled Trial. BMJ open 7 (9), e017652. doi:10.1136/ bmjopen-2017-017652

Nyamba, I., Lechanteur, A., Semdé, R., and Evrard, B. (2021). Physical Formulation Approaches for Improving Aqueous Solubility and Bioavailability of Ellagic Acid: A Review. Eur. J. Pharm. Biopharm. 159, 198-210. doi:10.1016/ j.ejpb.2020.11.004

Oliviero, F., Sfriso, P., Scanu, A., Fiocco, U., Spinella, P., and Punzi, L. (2013). Epigallocatechin-3-gallate Reduces Inflammation Induced by Calcium Pyrophosphate Crystals In Vitro. Front Pharmacol. 4, 51. doi:10.3389/ fphar.2013.00051

Ouyang, J., Jiang, H., Fang, H., Cui, W., and Cai, D. (2017). Isoimperatorin Ameliorates Osteoarthritis by Downregulating the Mammalian Target of Rapamycin C1 Signaling Pathway. Mol. Med. Rep. 16 (6), 9636-9644. doi:10.3892/mmr.2017.7777
Padmavathi, G., Roy, N. K., Bordoloi, D., Arfuso, F., Mishra, S., Sethi, G., et al. (2017). Butein in Health and Disease: A Comprehensive Review. Phytomedicine 25, 118-127. doi:10.1016/j.phymed.2016.12.002

Pan, L., Zhang, Y., Chen, N., and Yang, L. (2017a). Icariin Regulates Cellular Functions and Gene Expression of Osteoarthritis Patient-Derived Human Fibroblast-like Synoviocytes. Int. J. Mol. Sci. 18 (12). doi:10.3390/ijms18122656

Pan, Y., Chen, D., Lu, Q., Liu, L., Li, X., and Li, Z. (2017b). Baicalin Prevents the Apoptosis of Endplate Chondrocytes by Inhibiting the Oxidative Stress Induced by $\mathrm{H} 2 \mathrm{O} 2$. Mol. Med. Rep. 16 (3), 2985-2991. doi:10.3892/ mmr.2017.6904

Panahi, Y., Rahimnia, A. R., Sharafi, M., Alishiri, G., Saburi, A., and Sahebkar, A. (2014). Curcuminoid Treatment for Knee Osteoarthritis: a Randomized Double-Blind Placebo-Controlled Trial. Phytother Res. 28 (11), 1625-1631. doi:10.1002/ptr.5174

Park, C. H., Yamabe, N., Noh, J. S., Kang, K. S., Tanaka, T., and Yokozawa, T. (2009). The Beneficial Effects of Morroniside on the Inflammatory Response and Lipid Metabolism in the Liver of Db/db Mice. Biol. Pharm. Bull 32 (10), 1734-1740. doi:10.1248/bpb.32.1734

Peng, S., Hu, C., Liu, X., Lei, L., He, G., Xiong, C., et al. (2020). Rhoifolin Regulates Oxidative Stress and Proinflammatory Cytokine Levels in Freund's AdjuvantInduced Rheumatoid Arthritis via Inhibition of NF-Kb. Braz. J. Med. Biol. Res. 53 (6), e9489. doi:10.1590/1414-431x20209489

Pérez-Arancibia, R., Ordoñez, J. L., Rivas, A., Pihán, P., Sagredo, A., Ahumada, U., et al. (2021). A Phenolic-Rich Extract from Ugni Molinae Berries Reduces Abnormal Protein Aggregation in a Cellular Model of Huntington's Disease. PloS one 16 (7), e0254834. doi:10.1371/journal.pone.0254834

Philp, A. M., Davis, E. T., and Jones, S. W. (2017). Developing Anti-inflammatory Therapeutics for Patients with Osteoarthritis. Rheumatology (Oxford) 56 (6), 869-881. doi:10.1093/rheumatology/kew278

Portal-Núñez, S., Esbrit, P., Alcaraz, M. J., and Largo, R. (2016). Oxidative Stress, Autophagy, Epigenetic Changes and Regulation by miRNAs as Potential Therapeutic Targets in Osteoarthritis. Biochem. Pharmacol. 108, 1-10. doi:10.1016/j.bcp.2015.12.012

Prasad, S., Tyagi, A. K., and Aggarwal, B. B. (2014). Recent Developments in Delivery, Bioavailability, Absorption and Metabolism of Curcumin: the golden Pigment from golden Spice. Cancer Res. Treat 46 (1), 2-18. doi:10.4143/ crt.2014.46.1.2

Qin, N., Wei, L., Li, W., Yang, W., Cai, L., Qian, Z., et al. (2017). Local Intraarticular Injection of Resveratrol Delays Cartilage Degeneration in C57BL/6 Mice by Inducing Autophagy via AMPK/mTOR Pathway. J. Pharmacol. Sci. 134 (3), 166-174. doi:10.1016/j.jphs.2017.06.002

Ranjan, A., Ramachandran, S., Gupta, N., Kaushik, I., Wright, S., Srivastava, S., et al. (2019). Role of Phytochemicals in Cancer Prevention. Int. J. Mol. Sci. 20 (20). doi:10.3390/ijms20204981

Rasheed, Z., Anbazhagan, A. N., Akhtar, N., Ramamurthy, S., Voss, F. R., and Haqqi, T. M. (2009). Green tea Polyphenol Epigallocatechin-3-Gallate Inhibits Advanced Glycation End Product-Induced Expression of Tumor Necrosis Factor-Alpha and Matrix Metalloproteinase-13 in Human Chondrocytes. Arthritis Res. Ther. 11 (3), R71. doi:10.1186/ar2700

Ren, J., and Zhang, Y. (2018). Targeting Autophagy in Aging and Aging-Related Cardiovascular Diseases. Trends Pharmacol. Sci. 39 (12), 1064-1076. doi:10.1016/j.tips.2018.10.005

Rim, Y. A., Nam, Y., and Ju, J. H. (2020). The Role of Chondrocyte Hypertrophy and Senescence in Osteoarthritis Initiation and Progression. Int. J. Mol. Sci. 21 (7). doi:10.3390/ijms21072358

Rivera, D., Allkin, R., Obón, C., Alcaraz, F., Verpoorte, R., and Heinrich, M. (2014). What Is in a Name? the Need for Accurate Scientific Nomenclature for Plants. J. Ethnopharmacol 152 (3), 393-402. doi:10.1016/j.jep.2013.12.022

Robinson, K., Mock, C., and Liang, D. (2015). Pre-formulation Studies of Resveratrol. Drug Dev. Ind. Pharm. 41 (9), 1464-1469. doi:10.3109/ 03639045.2014.958753

Robinson, W. H., Lepus, C. M., Wang, Q., Raghu, H., Mao, R., Lindstrom, T. M., et al. (2016). Low-grade Inflammation as a Key Mediator of the Pathogenesis of Osteoarthritis. Nat. Rev. Rheumatol. 12 (10), 580-592. doi:10.1038/ nrrheum.2016.136

Roca-Agujetas, V., de Dios, C., Lestón, L., Marí, M., Morales, A., and Colell, A. (2019). Recent Insights into the Mitochondrial Role in Autophagy and its 
Regulation by Oxidative Stress. Oxid Med. Cell Longev 2019, 3809308. doi:10.1155/2019/3809308

Rodríguez-Hernández, K. D., Martínez, I., Reyes-Chilpa, R., and Espinoza, B. (2020). Mammea Type Coumarins Isolated from Calophyllum Brasiliense Induced Apoptotic Cell Death of Trypanosoma Cruzi through Mitochondrial Dysfunction, ROS Production and Cell Cycle Alterations. Bioorg. Chem. 100, 103894. doi:10.1016/j.bioorg.2020.103894

Rosillo, M. Á., Alcaraz, M. J., Sánchez-Hidalgo, M., Fernández-Bolaños, J. G., Alarcón-de-la-Lastra, C., and Ferrándiz, M. L. (2014). Anti-inflammatory and Joint Protective Effects of Extra-virgin Olive-Oil Polyphenol Extract in Experimental Arthritis. J. Nutr. Biochem. 25 (12), 1275-1281. doi:10.1016/ j.jnutbio.2014.07.006

Sachdeva, A. K., and Chopra, K. (2015). Lycopene Abrogates A $\beta(1-42)$-Mediated Neuroinflammatory cascade in an Experimental Model of Alzheimer's Disease. J. Nutr. Biochem. 26 (7), 736-744. doi:10.1016/j.jnutbio.2015.01.012

Salucci, S., Burattini, S., Giordano, F. M., Lucarini, S., Diamantini, G., and Falcieri, E. (2017). Further Highlighting on the Prevention of Oxidative Damage by Polyphenol-Rich Wine Extracts. J. Med. Food 20 (4), 410-419. doi:10.1089/ jmf.2016.0153

Sellés, A. J. N., Villa, D. G., and Rastrelli, L. (2015). Mango Polyphenols and its Protective Effects on Diseases Associated to Oxidative Stress. Curr. Pharm. Biotechnol. 16 (3), 272-280.

Silva, S., Sepodes, B., Rocha, J., Direito, R., Fernandes, A., Brites, D., et al. (2015). Protective Effects of Hydroxytyrosol-Supplemented Refined Olive Oil in Animal Models of Acute Inflammation and Rheumatoid Arthritis. J. Nutr. Biochem. 26 (4), 360-368. doi:10.1016/j.jnutbio.2014.11.011

Simmler, C., Pauli, G. F., and Chen, S. N. (2013). Phytochemistry and Biological Properties of Glabridin. Fitoterapia 90, 160-184. doi:10.1016/j.fitote.2013.07.003

Sofat, N., Ejindu, V., and Kiely, P. (2011). What Makes Osteoarthritis Painful? the Evidence for Local and central Pain Processing. Rheumatology (Oxford) 50 (12), 2157-2165. doi:10.1093/rheumatology/ker283

Sohn, M., Kim, K., Uddin, M. J., Lee, G., Hwang, I., Kang, H., et al. (2017). Delayed Treatment with Fenofibrate Protects against High-Fat Diet-Induced Kidney Injury in Mice: the Possible Role of AMPK Autophagy. Am. J. Physiol. Ren. Physiol 312 (2), F323-F334. doi:10.1152/ajprenal.00596.2015

Steimer, S. S., Berkemeier, T., Gilgen, A., Krieger, U. K., Peter, T., Shiraiwa, M., et al. (2015). Shikimic Acid Ozonolysis Kinetics of the Transition from Liquid Aqueous Solution to Highly Viscous Glass. Phys. Chem. Chem. Phys. 17 (46), 31101-31109. doi:10.1039/c5cp04544d

Sun, X., Deng, X., Cai, W., Li, W., Shen, Z., Jiang, T., et al. (2018). Icariin Inhibits LPS-Induced Cell Inflammatory Response by Promoting GRa Nuclear Translocation and Upregulating GRa Expression. Life Sci. 195, 33-43. doi:10.1016/j.lfs.2018.01.006

Sun, Y., Yao, Y., and Ding, C. Z. (2014). A Combination of Sinomenine and Methotrexate Reduces Joint Damage of Collagen Induced Arthritis in Rats by Modulating Osteoclast-Related Cytokines. Int. Immunopharmacol 18 (1), 135-141. doi:10.1016/j.intimp.2013.11.014

Takeda, R., Koike, T., Taniguchi, I., and Tanaka, K. (2013). Double-blind PlaceboControlled Trial of Hydroxytyrosol of Olea Europaea on Pain in Gonarthrosis. Phytomedicine 20 (10), 861-864. doi:10.1016/j.phymed.2013.03.021

Tang, W., Lin, D., Chen, M., Li, Z., Zhang, W., Hu, W., et al. (2019). PTENmediated Mitophagy and APE1 Overexpression Protects against Cardiac Hypoxia/reoxygenation Injury. In Vitro Cell Dev Biol Anim 55 (9), 741-748. doi:10.1007/s11626-019-00389-6

Tang, Y., Li, Y., Xin, D., Chen, L., Xiong, Z., and Yu, X. (2021). Icariin Alleviates Osteoarthritis by Regulating Autophagy of Chondrocytes by Mediating PI3K/ AKT/mTOR Signaling. Bioengineered 12 (1), 2984-2999. doi:10.1080/ 21655979.2021.1943602

Tang, Y., Mo, Y., Xin, D., Zeng, L., Yue, Z., and Xu, C. (2020). $\beta$-Ecdysterone Alleviates Osteoarthritis by Activating Autophagy in Chondrocytes through Regulating PI3K/AKT/mTOR Signal Pathway. Am. J. Transl Res. 12 (11), 7174-7186.

Taniguchi, N., Caramés, B., Ronfani, L., Ulmer, U., Komiya, S., Bianchi, M. E., et al. (2009). Aging-related Loss of the Chromatin Protein HMGB2 in Articular Cartilage Is Linked to Reduced Cellularity and Osteoarthritis. Proc. Natl. Acad. Sci. U S A. 106 (4), 1181-1186. doi:10.1073/pnas.0806062106

Togano, S., Yashiro, M., Masuda, G., Sugimoto, A., Miki, Y., Yamamoto, Y., et al. (2021). Gastric Cancer Stem Cells Survive in Stress Environments via Their Autophagy System. Sci. Rep. 11 (1), 20664. doi:10.1038/s41598-021-00155-3
Tu, Y. (1999). The Development of New Antimalarial Drugs: Qinghaosu and Dihydro-Qinghaosu. Chin Med. J. (Engl) 112 (11), 976-977.

Valsamidou, E., Gioxari, A., Amerikanou, C., Zoumpoulakis, P., Skarpas, G., and Kaliora, A. C. (2021). Dietary Interventions with Polyphenols in Osteoarthritis: A Systematic Review Directed from the Preclinical Data to Randomized Clinical Studies. Nutrients 13 (5). doi:10.3390/nu13051420

Varela-Eirín, M., Carpintero-Fernández, P., Sánchez-Temprano, A., VarelaVázquez, A., Paíno, C. L., Casado-Díaz, A., et al. (2020). Senolytic Activity of Small Molecular Polyphenols from Olive Restores Chondrocyte Redifferentiation and Promotes a Pro-regenerative Environment in Osteoarthritis. Aging 12 (16), 15882-15905. doi:10.18632/aging.103801

Veratti, E., Rossi, T., Giudice, S., Benassi, L., Bertazzoni, G., Morini, D., et al. (2011). 18beta-glycyrrhetinic Acid and Glabridin Prevent Oxidative DNA Fragmentation in UVB-Irradiated Human Keratinocyte Cultures. Anticancer Res. 31 (6), 2209-2215.

Vinatier, C., Domínguez, E., Guicheux, J., and Caramés, B. (2018). Role of the Inflammation-Autophagy-Senescence Integrative Network in Osteoarthritis. Front Physiol. 9, 706. doi:10.3389/fphys.2018.00706

Wang, B., and Chen, M. Z. (2014). Astragaloside IV Possesses Antiarthritic Effect by Preventing Interleukin $1 \beta$-Induced Joint Inflammation and Cartilage Damage. Arch. Pharm. Res. 37 (6), 793-802. doi:10.1007/s12272-014-0336-2

Wang, C. Z., Mehendale, S. R., and Yuan, C. S. (2007). Commonly Used Antioxidant Botanicals: Active Constituents and Their Potential Role in Cardiovascular Illness. Am. J. Chin Med. 35 (4), 543-558. doi:10.1142/ S0192415X07005053

Wang, T., and He, C. (2018). Pro-inflammatory Cytokines: The Link between Obesity and Osteoarthritis. Cytokine Growth Factor Rev. 44, 38-50. doi:10.1016/j.cytogfr.2018.10.002

Wang, W., Xu, J., Li, L., Wang, P., Ji, X., Ai, H., et al. (2010). Neuroprotective Effect of Morroniside on Focal Cerebral Ischemia in Rats. Brain Res. Bull 83 (5), 196-201. doi:10.1016/j.brainresbull.2010.07.003

Wang, Y., Smith, S., Teichtahl, A. J., Hodge, A. M., Wluka, A. E., Giles, G. G., et al. (2016). Association between Dietary Intake of Antioxidants and Prevalence of Femoral Head Cartilage Defects and Bone Marrow Lesions in CommunityBased Adults. J. Rheumatol. 43 (10), 1885-1890. doi:10.3899/jrheum.160325

Wang, Z., Lee, Y., Eun, J. S., and Bae, E. J. (2014). Inhibition of Adipocyte Inflammation and Macrophage Chemotaxis by Butein. Eur. J. Pharmacol. 738, 40-48. doi:10.1016/j.ejphar.2014.05.031

Wei, Y., and Ito, Y. (2006). Preparative isolation of imperatorin, oxypeucedanin and isoimperatorin from traditional Chinese herb "Bai zhi"Angelica dahurica (Fisch. ex Hoffm) Benth. et Hook using multidimensional high-speed countercurrent chromatography. J. Chromatogr. A. 1115 (1-2), 112-117. doi:10.1016/ j.chroma.2006.02.081

Wei, Y., Vriesekoop, F., Yuan, Q., and Liang, H. (2018). $\beta$-Lactoglobulin as a Nanotransporter for Glabridin: Exploring the Binding Properties and Bioactivity Influences. ACS Omega 3 (9), 12246-12252. doi:10.1021/acsomega.8b01576

Wong, R. H. X., Evans, H. M., and Howe, P. R. C. (2017). Resveratrol Supplementation Reduces Pain Experience by Postmenopausal Women. Menopause 24 (8), 916-922. doi:10.1097/gme.0000000000000861

Wongwichai, T., Teeyakasem, P., Pruksakorn, D., Kongtawelert, P., and Pothacharoen, P. (2019). Anthocyanins and Metabolites from Purple rice Inhibit IL-1 $\beta$-induced Matrix Metalloproteinases Expression in Human Articular Chondrocytes through the NF-Kb and ERK/MAPK Pathway. Biomed. Pharmacother. 112, 108610. doi:10.1016/j.biopha.2019.108610

Wu, L., Liu, H., Li, L., Liu, H., Cheng, Q., Li, H., et al. (2014). Mitochondrial Pathology in Osteoarthritic Chondrocytes. Curr. Drug Targets 15 (7), 710-719. doi:10.2174/1389450115666140417120305

Wu, X., Liu, Y., Zhang, E., Chen, J., Huang, X., Yan, H., et al. (2020). Dihydroartemisinin Modulates Apoptosis and Autophagy in Multiple Myeloma through the P38/MAPK and Wnt/ $\beta$-Catenin Signaling Pathways. Oxid Med. Cell Longev 2020, 6096391. doi:10.1155/2020/6096391

Wu, Z., Zhang, X., Li, Z., Wen, Z., and Lin, Y. (2021). Activation of Autophagy Contributes to the Protective Effects of Lycopene against Oxidative StressInduced Apoptosis in Rat Chondrocytes. Phytother Res. 35 (7), 4032-4045. doi:10.1002/ptr.7127

Xiao, Z., Wang, J., Chen, S., and Feng, Y. (2020). Autophagy Promotion Enhances the Protective Effect of Morroniside on Human OA Chondrocyte. Biosci. Biotechnol. Biochem. 84 (5), 989-996. doi:10.1080/09168451.2020.1717925 
Xing, J., Chen, X., and Zhong, D. (2005). Absorption and Enterohepatic Circulation of Baicalin in Rats. Life Sci. 78 (2), 140-146. doi:10.1016/j.lfs.2005.04.072

Xu, T., Niu, C., Zhang, X., and Dong, M. (2018). $\beta$-Ecdysterone Protects SH-Sy5y Cells against $\beta$-amyloid-induced Apoptosis via C-Jun N-Terminal Kinase- and Akt-Associated Complementary Pathways. Lab Invest 98 (4), 489-499. doi:10.1038/s41374-017-0009-0

Yan, C., Sun, W., Wang, X., Long, J., Liu, X., Feng, Z., et al. (2016). Punicalagin Attenuates Palmitate-Induced Lipotoxicity in HepG2 Cells by Activating the Keap1-Nrf2 Antioxidant Defense System. Mol. Nutr. Food Res. 60 (5), 1139-1149. doi:10.1002/mnfr.201500490

Yan, J., Ni, B., Sheng, G., Zhang, Y., Xiao, Y., Ma, Y., et al. (2021). Rhoifolin Ameliorates Osteoarthritis via Regulating Autophagy. Front Pharmacol. 12, 661072. doi:10.3389/fphar.2021.661072

Yang, H., Chen, D., Cui, Q. C., Yuan, X., and Dou, Q. P. (2006). Celastrol, a Triterpene Extracted from the Chinese "Thunder of God Vine," Is a Potent Proteasome Inhibitor and Suppresses Human Prostate Cancer Growth in Nude Mice. Cancer Res. 66 (9), 4758-4765. doi:10.1158/0008-5472.CAN-05-4529

Yang, K. Y., Lin, L. C., Tseng, T. Y., Wang, S. C., and Tsai, T. H. (2007). Oral Bioavailability of Curcumin in Rat and the Herbal Analysis from Curcuma Longa by LC-MS/MS. J. Chromatogr. B Analyt Technol. Biomed. Life Sci. 853 (12), 183-189. doi:10.1016/j.jchromb.2007.03.010

Yang, X., Zhang, Q., Gao, Z., Yu, C., and Zhang, L. (2018). Baicalin Alleviates IL-1 $\beta$ induced Inflammatory Injury via Down-Regulating miR-126 in Chondrocytes. Biomed. Pharmacother. 99, 184-190. doi:10.1016/j.biopha.2018.01.041

Yao, J., Liu, X., Sun, Y., Dong, X., Liu, L., and Gu, H. (2021). Curcumin-Alleviated Osteoarthritic Progression in Rats Fed a High-Fat Diet by Inhibiting Apoptosis and Activating Autophagy via Modulation of MicroRNA-34a. J. Inflamm. Res. 14, 2317-2331. doi:10.2147/JIR.S312139

You, H., Zhang, R., Wang, L., Pan, Q., Mao, Z., and Huang, X. (2021). ChondroProtective Effects of Shikimic Acid on Osteoarthritis via Restoring Impaired Autophagy and Suppressing the MAPK/NF- $\mathrm{KB}$ Signaling Pathway. Front Pharmacol. 12, 634822. doi:10.3389/fphar.2021.634822

Yu, H., Yao, S., Zhou, C., Fu, F., Luo, H., Du, W., et al. (2021). Morroniside Attenuates Apoptosis and Pyroptosis of Chondrocytes and Ameliorates Osteoarthritic Development by Inhibiting NF-Kb Signaling. J. Ethnopharmacol 266, 113447. doi:10.1016/j.jep.2020.113447

Yu, L., Chen, Y., and Tooze, S. A. (2018). Autophagy Pathway: Cellular and Molecular Mechanisms. Autophagy 14 (2), 207-215. doi:10.1080/ 15548627.2017.1378838

Yu, L. M., Dong, X., Xue, X. D., Zhang, J., Li, Z., Wu, H. J., et al. (2019). Protection of the Myocardium against Ischemia/reperfusion Injury by Punicalagin through an SIRT1-NRF-2-HO-1-dependent Mechanism. Chem. Biol. Interact 306, 152-162. doi:10.1016/j.cbi.2019.05.003

Yun, H. R., Jo, Y. H., Kim, J., Shin, Y., Kim, S. S., and Choi, T. G. (2020). Roles of Autophagy in Oxidative Stress. Int. J. Mol. Sci. 21 (9). doi:10.3390/ ijms 21093289

Zada, S., Pham, T. M., Hwang, J. S., Ahmed, M., Lai, T. H., Elashkar, O., et al. (2021). Chlorogenic Acid Protects Human Chondrocyte C28/I2 Cells from Oxidative Stress-Induced Cell Death through Activation of Autophagy. Life Sci. 285, 119968. doi:10.1016/j.lff.2021.119968

Zater, H., Huet, J., Fontaine, V., Benayache, S., Stévigny, C., Duez, P., et al. (2016). Chemical Constituents, Cytotoxic, Antifungal and Antimicrobial Properties of Centaurea Diluta Ait. Subsp. Algeriensis (Coss. \& Dur.) Maire. Asian Pac. J. Trop. Med. 9 (6), 554-561. doi:10.1016/j.apjtm.2016.04.016

Zeng, L., Wang, W., Rong, X. F., Zhong, Y., Jia, P., Zhou, G. Q., et al. (2014). Chondroprotective Effects and Multi-Target Mechanisms of Icariin in IL-1 BetaInduced Human SW 1353 Chondrosarcoma Cells and a Rat Osteoarthritis Model. Int. Immunopharmacol 18 (1), 175-181. doi:10.1016/j.intimp.2013.11.021

Zhang, G., Cao, J., Yang, E., Liang, B., Ding, J., Liang, J., et al. (2018a). Curcumin Improves Age-Related and Surgically Induced Osteoarthritis by Promoting Autophagy in Mice. Biosci. Rep. 38 (4). doi:10.1042/bsr20171691

Zhang, G., Zhang, H., You, W., Tang, X., Li, X., and Gong, Z. (2020). Therapeutic Effect of Resveratrol in the Treatment of Osteoarthritis via the MALAT1/miR9/nf-Kb Signaling Pathway. Exp. Ther. Med. 19 (3), 2343-2352. doi:10.3892/ etm.2020.8471

Zhang, J., Wang, S., Rong, G., Cheng, F., Gui, B., and Shen, C. (2018b). Tetrahydrohyperforin Prevents Articular Cartilage Degeneration and Affects
Autophagy in Rats with Osteoarthritis. Exp. Ther. Med. 15 (6), 5261-5268. doi:10.3892/etm.2018.6098

Zhang, R. J., Cai, C., Pang, J., Xu, X. L., and Li, G. W. (2021). Therapeutic Effect of Huzhangoside D in Rats with Knee Osteoarthritis Induced by Anterior Cruciate Ligament Transection. Pharmacogn Mag. 17 (73), 112.

Zhang, W., Ouyang, H., Dass, C. R., and Xu, J. (2016). Current Research on Pharmacologic and Regenerative Therapies for Osteoarthritis. Bone Res. 4, 15040. doi:10.1038/boneres.2015.40

Zhang, X., Xu, X., Xu, T., and Qin, S. (2014). $\beta$-Ecdysterone Suppresses Interleukin$1 \beta$-Induced Apoptosis and Inflammation in Rat Chondrocytes via Inhibition of NF-Kb Signaling Pathway. Drug Dev. Res. 75 (3), 195-201. doi:10.1002/ ddr.21170

Zhang, Y., Wang, Q. S., Cui, Y. L., Meng, F. C., and Lin, K. M. (2012). Changes in the Intestinal Absorption Mechanism of Icariin in the Nanocavities of Cyclodextrins. Int. J. Nanomedicine 7, 4239-4249. doi:10.2147/ IJN.S33014

Zhang, Y., Zhang, Y., Li, J., Chen, Y., Han, L., He, Q., et al. (2019). The Role of Hepatic Antioxidant Capacity and Hepatobiliary Transporter in Liver Injury Induced by Isopsoralen in Zebrafish Larvae. Hum. Exp. Toxicol. 38 (1), 36-44. doi:10.1177/0960327118774873

Zhang, Y. J., Gan, R. Y., Li, S., Zhou, Y., Li, A. N., Xu, D. P., et al. (2015). Antioxidant Phytochemicals for the Prevention and Treatment of Chronic Diseases. Molecules 20 (12), 21138-21156. doi:10.3390/molecules201219753

Zhao, H., Zhang, T., Xia, C., Shi, L., Wang, S., Zheng, X., et al. (2014). Berberine Ameliorates Cartilage Degeneration in Interleukin-1 $\beta$-Stimulated Rat Chondrocytes and in a Rat Model of Osteoarthritis via Akt Signalling. J. Cell Mol Med 18 (2), 283-292. doi:10.1111/jcmm.12186

Zheng, W., Zhang, H., Jin, Y., Wang, Q., Chen, L., Feng, Z., et al. (2017). Butein Inhibits IL-1 $\beta$-induced Inflammatory Response in Human Osteoarthritis Chondrocytes and Slows the Progression of Osteoarthritis in Mice. Int. Immunopharmacol 42, 1-10. doi:10.1016/j.intimp.2016.11.009

Zhi, L. Q., Yao, S. X., Liu, H. L., Li, M., Duan, N., and Ma, J. B. (2018). Hydroxytyrosol Inhibits the Inflammatory Response of Osteoarthritis Chondrocytes via SIRT6-Mediated Autophagy. Mol. Med. Rep. 17 (3), 4035-4042. doi: $10.3892 / \mathrm{mmr} .2017 .8353$

Zhou, J.-c., Wang, J.-l., Ren, H.-z., and Shi, X.-l. (2021a). Autophagy Plays a Double-Edged Sword Role in Liver Diseases. J. Physiol. Biochem. 2021, 298. doi:10.1007/s13105-021-00844-7

Zhou, L., Liu, Q., Yang, M., Wang, T., Yao, J., Cheng, J., et al. (2016). Dihydroartemisinin, an Anti-malaria Drug, Suppresses Estrogen DeficiencyInduced Osteoporosis, Osteoclast Formation, and RANKL-Induced Signaling Pathways. J. Bone Miner Res. 31 (5), 964-974. doi:10.1002/jbmr.2771

Zhou, P., Xie, W., Meng, X., Zhai, Y., Dong, X., Zhang, X., et al. (2019). Notoginsenoside R1 Ameliorates Diabetic Retinopathy through PINK1dependent Activation of Mitophagy. Cells 8 (3), 213. doi:10.3390/cells8030213

Zhou, W., Shi, Y., Wang, H., Yu, C., Zhu, H., and Wu, A. (2021b). Sinensetin Reduces Osteoarthritis Pathology in the Tert-Butyl Hydroperoxide-Treated Chondrocytes and the Destabilization of the Medial Meniscus Model Mice via the AMPK/mTOR Signaling Pathway. Front Pharmacol. 12, 713491. doi:10.3389/fphar.2021.713491

Conflict of Interest: The authors declare that the research was conducted in the absence of any commercial or financial relationships that could be construed as a potential conflict of interest.

Publisher's Note: All claims expressed in this article are solely those of the authors and do not necessarily represent those of their affiliated organizations, or those of the publisher, the editors and the reviewers. Any product that may be evaluated in this article, or claim that may be made by its manufacturer, is not guaranteed or endorsed by the publisher.

Copyright (c) 2021 Tian, Zhang and Sun. This is an open-access article distributed under the terms of the Creative Commons Attribution License (CC BY). The use, distribution or reproduction in other forums is permitted, provided the original author(s) and the copyright owner(s) are credited and that the original publication in this journal is cited, in accordance with accepted academic practice. No use, distribution or reproduction is permitted which does not comply with these terms. 